\title{
Comparative dissolution kinetics of biogenic and chemogenic uraninite under oxidizing conditions in the presence of carbonate
}

\author{
Kai-Uwe Ulrich $^{\mathrm{a}, *}$, Eugene S. Ilton ${ }^{\mathrm{b}}$, Harish Veeramani ${ }^{\mathrm{c}}$, Jonathan O. Sharp ${ }^{\mathrm{c}, 1}$, \\ Rizlan Bernier-Latmani ${ }^{\text {c }}$, Eleanor J. Schofield ${ }^{\mathrm{d}, 2}$, John R. Bargar ${ }^{\mathrm{d}}$, \\ Daniel E. Giammar ${ }^{\mathrm{a}}$ \\ a Department of Energy, Environmental and Chemical Engineering, Washington University, One Brookings Drive, St. Louis, MO 63130, USA \\ ${ }^{\mathrm{b}}$ Pacific Northwest National Laboratory, 902 Battelle Blvd, Richland, WA 99352, USA \\ ${ }^{\mathrm{c}}$ Ecole Polytechnique Fédérale de Lausanne, CH-1015 Lausanne, Switzerland \\ ${ }^{\mathrm{d}}$ Stanford Synchrotron Radiation Lightsource, 2575 Sand Hill Rd, Menlo Park, CA 94025, USA
}

Received 8 January 2009; accepted in revised form 9 July 2009; available online 14 July 2009

\begin{abstract}
The long-term stability of biogenic uraninite with respect to oxidative dissolution is pivotal to the success of in situ bioreduction strategies for the subsurface remediation of uranium legacies. Batch and flow-through dissolution experiments were conducted along with spectroscopic analyses to compare biogenic uraninite nanoparticles obtained from Shewanella oneidensis MR-1 and chemogenic $\mathrm{UO}_{2.00}$ with respect to their equilibrium solubility, dissolution mechanisms, and dissolution kinetics in water of varied oxygen and carbonate concentrations. Both materials exhibited a similar intrinsic solubility of $\sim 10^{-8} \mathrm{M}$ under reducing conditions. The two materials had comparable dissolution rates under anoxic as well as oxidizing conditions, consistent with structural bulk homology of biogenic and stoichiometric uraninite. Carbonate reversibly promoted uraninite dissolution under both moderately oxidizing and reducing conditions, and the biogenic material yielded higher surface areanormalized dissolution rates than the chemogenic. This difference is in accordance with the higher proportion of $U(V)$ detected on the biogenic uraninite surface by means of X-ray photoelectron spectroscopy. Reasonable sources of a stable $\mathrm{U}(\mathrm{V})$-bearing intermediate phase are discussed. The observed increase of the dissolution rates can be explained by carbonate complexation of $\mathrm{U}(\mathrm{V})$ facilitating the detachment of $\mathrm{U}(\mathrm{V})$ from the uraninite surface. The fraction of surface-associated U(VI) increased with dissolved oxygen concentration. Simultaneously, X-ray absorption spectra showed conversion of the bulk from $\mathrm{UO}_{2.0}$ to $\mathrm{UO}_{2+x}$. In equilibrium with air, combined spectroscopic results support the formation of a near-surface layer of approximate composition $\mathrm{UO}_{2.25}\left(\mathrm{U}_{4} \mathrm{O}_{9}\right)$ coated by an outer layer of $\mathrm{U}(\mathrm{VI})$. This result is in accordance with flowthrough dissolution experiments that indicate control of the dissolution rate of surface-oxidized uraninite by the solubility of metaschoepite under the tested conditions. Although $\mathrm{U}(\mathrm{V})$ has been observed in electrochemical studies on the dissolution of spent nuclear fuel, this is the first investigation that demonstrates the formation of a stable $U(V)$ intermediate phase on the surface of submicron-sized uraninite particles suspended in aqueous solutions.
\end{abstract}

(c) 2009 Elsevier Ltd. All rights reserved.

\footnotetext{
* Corresponding author. Present address: BGD Soil and Groundwater Laboratory GmbH, Tiergartenstrasse 48, D-01219 Dresden, Germany. Fax: +49 35143899039.

E-mail address: kulrich@bgd-gmbh.de (K.-U. Ulrich).

${ }^{1}$ Present address: Colorado School of Mines, Environmental Science \& Engineering Division, Golden, CO.

2 Present address: The University of Kent, School of Physical Sciences, Canterbury, Kent, UK.
}

\section{INTRODUCTION}

The anthropogenic use of uranium (U) for nuclear fuel production, weapons manufacturing and research has resulted in widespread contamination of soils and groundwater. One of the most stable natural forms of uranium is uraninite, a hyperstoichiometric mineral in the range of $\mathrm{UO}_{2+x}(0<x<0.25)$ that ubiquitously contains impurities 
when present in rock or sediment formations (Finch and Ewing, 1992; Janeczek and Ewing, 1992a,b). Because several species of metal and sulfate reducing bacteria are known to mediate the reduction of dissolved U(VI) to U(IV) (Suzuki and Suko, 2006; Wall and Krumholz, 2006), the engineered stimulation of microbial growth in contaminated media by providing an electron donating carbon source (e.g., ethanol, acetate, lactate, glucose) has been proposed to initiate the precipitation of sparingly soluble uraninite (Gorby and Lovley, 1992; Lovley and Phillips, 1992; Lovley et al., 1991). This strategy of in situ bioremediation has been studied for more than a decade (N'Guessan et al., 2008; Renshaw et al., 2007 and references therein). Uranium immobilization can only be successful if dissolution rates of biogenic uraninite and the likelihood of reoxidation are low. Although the structure of biogenically immobilized uranium has not yet been fully characterized in field-scale U(VI) bioreduction experiments, nanoparticulate $\mathrm{UO}_{2+x}$ obtained from cell cultures is better understood and typically exhibits a composition close to $\mathrm{UO}_{2.0}$ (Burgos et al., 2008; Schofield et al., 2008; Singer et al., 2007, 2009). Hence, even more knowledge is required with respect to the chemical stability of biogenic $\mathrm{UO}_{2+x}$, in particular the kinetics of dissolution reactions under environmentally relevant scenarios. In this paper, the term "bio- $\mathrm{UO}_{2}$ " is used for biogenic uraninite prepared in the absence of dopants, irrespective of the actual stoichiometry (the number of $x$ in $\mathrm{UO}_{2+x}$ ). Unless otherwise specified, the term "syn- $\mathrm{UO}_{2}$ " is used for chemogenic $\mathrm{UO}_{2+x}$ where the stoichiometry may range between $0 \leqslant x \leqslant 0.33$ dependent on the chemical conditions present and the degree of surface oxidation.

In natural groundwater, the potential of the U(IV)/ $\mathrm{U}(\mathrm{VI})$ redox couple is expected to range between -42 and $+86 \mathrm{mV}$, depending on a number of parameters including the $\mathrm{pH}$ and concentrations of $\mathrm{Ca}^{2+}$ and dissolved inorganic carbon (DIC) (Brooks et al., 2003; Wall and Krumholz, 2006). Some of the most potent electron acceptors for U(IV) oxidation are dissolved oxygen, nitrate, nitrite, and solid $\mathrm{Mn}(\mathrm{IV})$ and $\mathrm{Fe}(\mathrm{III})$. The processes of biogenic uraninite reoxidation and its suppression have been investigated for lab-grown cultures and sediments amended with a carbon source in situ or in flow-through columns. Dissolved oxygen (DO) is one of the strongest oxidants of U(IV), and it has been reported to oxidize bioreduced U(IV) within several hours to days in stirred batch experiments (half-life of $\leqslant 1 \mathrm{~h}$ ) ( $\mathrm{Gu}$ et al., 2005; Zhou and $\mathrm{Gu}, 2005$ ) or when mixed with bioreduced sediment (Zhong et al., 2005). However, continuous-flow-through dissolution studies using bioreduced sediments in soil columns demonstrated that nitrate and not DO can be the dominant oxidant of U(IV) in sediments. The authors hypothesized that oxygen was scavenged more rapidly by other reduced compounds or by microbial metabolism (Moon et al., 2007). In addition to nitrate, which is often found in U-contaminated sites (Finneran et al., 2002), intermediate products of dissimilatory nitrate reduction or denitrification such as $\mathrm{NO}_{2}{ }^{-}, \mathrm{N}_{2} \mathrm{O}$ and NO can oxidize and remobilize U(IV) (Senko et al., 2002).

$\mathrm{Mn}$ oxides can rapidly oxidize bio- $\mathrm{UO}_{2}$ in the absence of biological activity (Fredrickson et al., 2002), and freshly formed biogenic $\mathrm{MnO}_{2}$ can be an even more effective oxidant for $\mathrm{UO}_{2+x}$ than DO under low partial pressure $\left(P_{\mathrm{O} 2}\right)$ conditions (Chinni et al., 2008). Ferrihydrite can rapidly oxidize bio- $\mathrm{UO}_{2}$, generating dissolved $\mathrm{U}(\mathrm{VI})$ and $\mathrm{Fe}^{2+}$. The oxidation rate is affected by the aqueous speciation of $\mathrm{U}(\mathrm{VI})$ which is a function of $\mathrm{pH}$, carbonate, and $\mathrm{Ca}^{2+}$ concentrations because those ions tend to form stable ternary complexes with U(VI) lowering the free energy of uraninite oxidation (Ginder-Vogel et al., 2006). Reactive $\mathrm{Fe}(\mathrm{III})$ oxyhydroxide can also result from enzymatic Fe(II) oxidation coupled to nitrate reduction, or from $\mathrm{Fe}(\mathrm{II})$ oxidation with nitrite (Senko et al., 2005a). Other work found that humic substances, siderophores, and (bi)carbonate from the degradation of organics can increase the rate of bio- $\mathrm{UO}_{2}$ oxidation by formation of stable $\mathrm{U}(\mathrm{VI})$ complexes (Frazier et al., 2005; Gu et al., 2005; Wan et al., 2005).

The stability of bio- $\mathrm{UO}_{2}$ can be enhanced by preventing reoxidation of $U(I V)$, for example when sulfides such as mackinawite $(\mathrm{FeS})$ or decaying biomass are present and act as oxygen-scavenging redox buffers or when sulfite is added to the system (Abdelouas et al., 1999; Wu et al., 2007). Another strategy for stabilizing bio- $\mathrm{UO}_{2}$ is to keep the rate of $\mathrm{U}(\mathrm{VI})$ bioreduction low, which may give rise to larger and more aggregated particles that are more resistant to oxidation (Senko et al., 2007). In batch experiments with air-equilibrated water, small particles of bio- $\mathrm{UO}_{2}$ were oxidized much faster than were larger particles and aggregates. However, the U(VI) bioreduction rate is not a unique tool to control particle size. This has been exemplified for Shewanella oneidensis MR-1 for which the bioreduction rate did not affect particle size in contrast to results from Shewanella putrefaciens CN32 (Burgos et al., 2008).

In most of the above-mentioned studies, the generated U(IV) phase has not been structurally characterized and there is little robust information regarding the stability of the solid phase. Although several authors have applied Xray absorption near-edge spectroscopy (XANES) to quantify the proportion of biogenic U(IV) and U(VI) in their systems, structural characterization of the U(IV) mineral phase is lacking in most $\mathrm{U}$ bioreduction - reoxidation studies (Ginder-Vogel et al., 2006; Senko et al., 2005b; Wan et al., 2005; Wu et al., 2007; Zhong et al., 2005). The combination of structural investigations with studies on dissolution kinetics is important because structural differences are expected to modulate chemical stability. For example, Finch and Ewing (1992) reported that cations incorporated in the uraninite lattice and a corrosion rind of U(VI) on the mineral surface inhibited further U(IV) oxidation. This made uraninite stable at redox conditions under which synthetic $\mathrm{UO}_{2}$ corrodes.

Recent research shows that the nano-sized $\mathrm{UO}_{2+x}$ material generated by lab-grown cultures of $S$. oneidensis MR-1 is near-stoichiometric $(x<0.05)$ and structurally similar to chemogenic $\mathrm{UO}_{2.00}$ (Schofield et al., 2008). A comparison of both types of material with respect to stability under reducing, carbonate-free conditions showed that dissolution rates had the same order of magnitude when normalized to surface area (Ulrich et al., 2008). The objective of the present study is to investigate the effects of carbonate and dissolved oxygen on the stability of biogenic and 
chemogenic $\mathrm{UO}_{2+x}$. Dissolution rates are presented as a function of varied DO and DIC concentrations, and a conceptual mechanistic model of possible surface reactions supported by spectroscopic results is discussed. The ultimate goal of this research is to predict the long-term stability of a structurally well-characterized biogenic uraninite under chemical conditions relevant to contaminated groundwater.

\section{EXPERIMENTAL SECTION}

\subsection{Materials}

Reagents of certified ACS grade or better and ultrapure water (resistivity $>18.5 \mathrm{M} \Omega \mathrm{cm}$ ) were used. The $\mathrm{UO}_{2+x}$ materials were prepared in an anaerobic chamber (Coy Laboratory Products) as described in Ulrich et al. (2008). Biogenic $\mathrm{UO}_{2+x}$ was produced by the facultative anaerobic $S$. oneidensis strain MR-1. Bacteria of the genus Shewanella have been found in the subsurface, e.g., at the Hanford site (Fredrickson et al., 2007). U(VI) reduction was carried out in the presence of $1.2 \mathrm{mM}$ uranyl acetate, $30 \mathrm{mM} \mathrm{NaHCO}_{3}$, and $20 \mathrm{mM}$ lactic acid at $\mathrm{pH} 6.3$ and 8.0 , giving rise to different ratios of $\mathrm{UO}_{2}\left(\mathrm{CO}_{3}\right)_{2}{ }^{2-}$ and $\mathrm{UO}_{2}\left(\mathrm{CO}_{3}\right)_{3}{ }^{4-}$ as the dominant $\mathrm{U}(\mathrm{VI})$ species under these conditions. The yield of U(IV) oxide was close to or above $99 \%$ at both $\mathrm{pH}$ conditions. The products are referred to as bio6- $\mathrm{UO}_{2}$ and bio8$\mathrm{UO}_{2}$. Upon completion of $\mathrm{U}(\mathrm{VI})$ bioreduction, the mixture of bio- $\mathrm{UO}_{2}$ and cells was treated overnight with $1 \mathrm{M}$ $\mathrm{NaOH}$. The organic debris was removed from $\mathrm{UO}_{2}$ by phase separation employing anaerobic hexane. Subsequent treatment with $0.1 \mathrm{M} \mathrm{NaHCO} 3$ solution and repeated washing with ultrapure anaerobic water removed less than $1 \%$ of the total uranium, presumably U(VI). The cleaned bio- $\mathrm{UO}_{2}$ solids were stored anaerobically in light-protected serum bottles until being used in dissolution experiments.

Synthetic uraninite $\left(\right.$ syn- $\left.\mathrm{UO}_{2}\right)$ was prepared by reduction of studtite $\left(\mathrm{UO}_{2} \mathrm{O}_{2} \cdot 4 \mathrm{H}_{2} \mathrm{O}_{(\mathrm{s})}\right)$ at $400{ }^{\circ} \mathrm{C}$ for $4 \mathrm{~h}$ in a stainless steel reactor in presence of $\mathrm{H}_{2(\mathrm{~g})}$ (Eq. (1)).

$\mathrm{UO}_{2} \mathrm{O}_{2} \cdot 4 \mathrm{H}_{2} \mathrm{O}_{(\mathrm{s})}+2 \mathrm{H}_{2(\mathrm{~g})} \rightarrow \mathrm{UO}_{2(\mathrm{~s})}+6 \mathrm{H}_{2} \mathrm{O}$

Studtite was precipitated by mixing $\sim 88 \mathrm{mM} \mathrm{H}_{2} \mathrm{O}_{2}$ (Sigma Aldrich) with $2.5 \mathrm{mM} \mathrm{UO} \mathrm{Cl}_{2}$ (Eq. (2)).

$\mathrm{UO}_{2} \mathrm{Cl}_{2}+\mathrm{H}_{2} \mathrm{O}_{2}+4 \mathrm{H}_{2} \mathrm{O} \rightarrow \mathrm{UO}_{2} \mathrm{O}_{2} \cdot 4 \mathrm{H}_{2} \mathrm{O}_{(\mathrm{s})}+2 \mathrm{HCl}$

A light yellow precipitate settled within 3 days. It was dialyzed against ultrapure water, dried, and identified as pure $\mathrm{UO}_{2} \mathrm{O}_{2} \cdot 4 \mathrm{H}_{2} \mathrm{O}_{(\mathrm{s})}$ by X-ray diffraction (XRD). The $\mathrm{UO}_{2} \mathrm{Cl}_{2}$ stock solution was prepared by heating $\mathrm{UO}_{2}\left(\mathrm{NO}_{3}\right)_{2} \cdot 6 \mathrm{H}_{2} \mathrm{O}$ (Antec, Inc.) at $275^{\circ} \mathrm{C}$ for 3 days to produce solid $\mathrm{UO}_{3}$ that was then dissolved in $0.5 \mathrm{M} \mathrm{HCl}$ (trace metal grade, Fisher Scientific).

\subsection{Structural properties of unreacted $\mathrm{UO}_{2+x}$}

The biogenic and synthetic materials differed notably in their particle size and surface area. The bio- $\mathrm{UO}_{2}$ particles exhibited a nano-scale size range of $1.5-3.5 \mathrm{~nm}$ (Schofield et al., 2008) and an average specific surface area of $50.1 \mathrm{~m}^{2} / \mathrm{g}$ obtained from multipoint $\mathrm{N}_{2}$-BET. This surface area is lower than expected for a spherical $\mathrm{UO}_{2}$ particle of that size $\left(150-360 \mathrm{~m}^{2} / \mathrm{g}\right)$, and it is lower than recently published $\mathrm{N}_{2}$-BET data of biogenic $\mathrm{UO}_{2}$ obtained from S. putrefaciens CN32 (93-129 m²/g, Singer et al., 2009), suggesting significant agglomeration of the nanoparticles. Because particle agglomeration could not be prevented over the course of dissolution experiments, the obtained dissolution rates were normalized to the measured rather than the calculated surface area. The mean diameter of the syn- $\mathrm{UO}_{2}$ particles was two orders of magnitude larger $(100-200 \mathrm{~nm})$ and revealed a matching $\mathrm{N}_{2}$-BET surface area of $5.9 \mathrm{~m}^{2} / \mathrm{g}$.

X-ray absorption spectroscopy and synchrotron based $\mathrm{X}$-ray powder diffraction results showed that the structures of the bio6- $\mathrm{UO}_{2}$ and bio8- $\mathrm{UO}_{2}$ materials were similar, suggesting particles with a highly ordered core in which the Ulattice is preserved (stoichiometry close to $\mathrm{UO}_{2.00}, x<0.05$ ) and an outer region with local disorder (Schofield et al., 2008; Ulrich et al., 2008). The lattice parameter of the uncleaned bio- $\mathrm{UO}_{2}$ was similar to that of chemogenic $\mathrm{UO}_{2.00}$, suggesting that the surface energy is not sufficient to strain the intermediate- and long-range structure of the bio- $\mathrm{UO}_{2}$ particles. Hence, similar intrinsic thermodynamic and kinetic properties would be expected.

\subsection{Dissolution experiments}

Dissolution rates were quantified using magneticallystirred continuous-flow tank reactors (CFR, volume of $12.6 \mathrm{~mL}$ ) operated in the dark at room temperature $\left(20 \pm 1{ }^{\circ} \mathrm{C}\right)$ as described in detail elsewhere (Ulrich et al., 2008). Each reactor was loaded with a weighed amount of syn- $\mathrm{UO}_{2}$ powder or a defined aliquot of well-mixed bio$\mathrm{UO}_{2}$ suspension with known $\mathrm{UO}_{2}$ concentration and fed with equilibrated solutions of given chemical composition. All feed solutions contained 1 or $5 \mathrm{mM}$ HEPES buffer adjusted to $\mathrm{pH} 7.5$ or 8.0. $\mathrm{NaHCO}_{3}$ was added to obtain DIC concentrations of $0.1,1.0$, or $10 \mathrm{mM}$. Customized gas mixtures were purged into the feed solution to maintain reducing conditions $\left(95 \% \mathrm{~N}_{2}+5 \% \mathrm{H}_{2}\right.$ in presence of a $\mathrm{Pd}$ catalyst) or oxidizing conditions with $1 \mathrm{vol} \% \mathrm{O}_{2}$ (balance $\mathrm{N}_{2}$ ) or $21 \mathrm{vol} \% \mathrm{O}_{2}$ (compressed air). Influent flow rates were set between 1.0 and $2.1 \mathrm{~mL} / \mathrm{min}$ and gravimetrically monitored based on the effluent volume collected in test tubes using an automatic fraction collector. The DO concentration of the influent was monitored with a flowthrough DO probe (Microelectrodes, Inc.) installed in the tubing between the feed reservoir and the CFR.

Because the available amount of biogenic $\mathrm{UO}_{2}$ was limited, the CFR experiments were carried out either in a consecutive or intermittent treatment mode. In the consecutive mode, different feed solutions were pumped through the CFR for about 40 residence times for each solution in a sequence of increasing $P_{\mathrm{O} 2}(0,1,21 \mathrm{vol} \%$ while maintaining $1 \mathrm{mM}$ DIC), or increasing concentration of carbonate $(0$, $0.1,1.0,10 \mathrm{mM}$ while maintaining $P_{\mathrm{O} 2}$ constant at $1 \mathrm{vol} \%$ ). Both series started with anoxic atmosphere using DIC-free, HEPES-buffered feed solution. The same condition was applied during the first and third treatment steps of the intermittent dissolution modes, interrupted by either 
feeding $1 \mathrm{mM}$ DIC under reducing conditions or providing DO equilibrated to a $1 \% P_{\mathrm{O} 2}$ headspace.

Equilibrium $[U]_{\text {diss }}$ of $\mathrm{UO}_{2}$ under reducing conditions was determined by switching the operation mode from flow-through (i.e., CFR) to stirred batch reactor (SBR). By operating in this order, any labile U(VI) species present with the initial solid were washed away during the CFR mode prior to starting the equilibrium measurement in the SBR mode. The SBR experiments were performed in a closed system in the glovebox. Samples for $U$ analysis were collected at several points in elapsed time using a needle syringe and filtered through aluminum oxide filter units (Anotop10, Whatman, Inc.) with $0.02 \mu \mathrm{m}$ pore size. For spectroscopic investigations, the residual solids of the suspension were either accumulated on a filter membrane or centrifuged. The wet paste was loaded into an aluminum sample holder with Kapton windows and stored at anoxic conditions until the analysis by X-ray absorption spectroscopy. For X-ray photoelectron spectroscopy, the wet samples were dried in an anaerobic chamber prior to the analysis.

\subsection{Analysis}

The $\mathrm{pH}$ was periodically measured in the feed solution and the effluent samples. Effluent samples selected for total $\mathrm{U}$ analysis were acidified to $0.1 \mathrm{M}$ nitric acid prior to measurement by ICP-MS (Agilent 7500ce). The ICP-MS method for uranium had a detection limit $<10 \mathrm{ng} / \mathrm{L}$. Several samples were also analyzed specifically for U(VI) using a kinetic phosphorescence analyzer (KPA) (Chemchek, Richland, WA, USA) with a detection limit of $<0.1 \mu \mathrm{g} / \mathrm{L}$ (Chinni et al., 2008).

X-ray absorption spectroscopy (XAS) and high-resolution X-ray photoelectron spectroscopy (XPS) were used to determine the redox state and stoichiometry of uranium in the bulk and near the surface of $\mathrm{UO}_{2+x}$ particles before and after their reaction in dissolution experiments.

\subsubsection{X-ray photoelectron spectroscopy}

The XPS analyses were carried out at Lehigh University using a Scienta ESCA300. The instrument's operational parameters as well as methodologies for coping with potential artifacts are discussed elsewhere (Ilton et al., 2004). Briefly, an intense monochromatic $\mathrm{Al} \mathrm{K} \alpha$ X-ray beam, which is generated with a rotating anode, was used. Operational conditions yielded Fermi edge widths of $0.41-0.31 \mathrm{eV}$ for $\mathrm{Ag}^{0}$, depending on the pass energy used. Regional scans of the $\mathrm{U} 4 f$ region were recorded and the energy scale was referenced to adventitious $\mathrm{C} 1 \mathrm{~s}$ at $285.0 \mathrm{eV}$. For a number of samples, and in particular for the uncleaned biogenic $\mathrm{UO}_{2}$ samples, the $\mathrm{C} 1 \mathrm{~s}$ structure was complicated. In such cases, the $\mathrm{C} 1 \mathrm{~s}$ peak was curve-resolved with a sufficient number of Gaussians to obtain a good fit. The lowest energy Gaussian was then set as the energy scale reference.

Standards for U(VI), U(V) and U(IV) were used to determine satellite structures and primary peak parameters. Schoepite was precipitated from a supersaturated solution and used as a U(VI) standard. A U(V)-U(VI) oxyhydroxide phase provided the standard for $\mathrm{U}(\mathrm{V})$. The synthesis and characterization of this compound has been described in detail in previous work (Belai et al., 2008). The U(V) component was derived by fitting the mixed valence phase with the U(VI) component (obtained from schoepite) and solving for the U(V) component. The U(IV) standard was prepared as described in Section 2.1 and characterized as stoichiometric $\mathrm{UO}_{2.00}$ by X-ray powder diffraction and XAS (Ulrich et al., 2008).

Spectra were best fit by non-linear least squares using the CasaXPS curve resolution software. A Shirley background was extended from about $8 \mathrm{eV}$ below the $4 f_{7 / 2}$ peak to about $20 \mathrm{eV}$ above the $4 f_{5 / 2}$ peak. This binding energy (BE) spread encompassed the major satellite features. The BE and intensity of individual components, which included satellites and primary peaks, were allowed to move as a packet relative to the other components (i.e., satellite-primary peak BE separations and relative intensities were fixed for a given component). A single, but variable full-width-athalf-maximum (FWHM) value was used for all the core peak components. Satellite and core peak FWHMs were set at a fixed ratio for each component. The outstanding energy resolution obtained by the Scienta300, combined with tightly correlating core peaks to their corresponding satellites, imposed severe constraints on the solution for each sample.

Prior to XPS analyses, the wet samples were dried and stored in an airtight container for $24-48 \mathrm{~h}$. The container was then placed in an Ar filled glove bag attached to the entry port of the X-ray photoelectron instrument such that the sample transfer occurred with minimal exposure to oxygen. Sequential analyses were taken on the same spot, for each specimen, in order to check for beam induced reduction. The sequential spectra for the U(IV) standard indicated no change, and the $\mathrm{U}(\mathrm{V})$ standard was stable over the first several spectra in the sequence. However, most other specimens, including the U(VI) standard, did indicate reduction over time. Fortunately, reduction was systematic and slow. In order to minimize the reduction of our U(VI) standard, it was analyzed at a lower photon flux. The XPS spectra presented in this work are always the first in each sequence. Tabulated data give both the valence state derived from the first spectrum in the sequence and a value obtained by extrapolating to time zero.

\subsubsection{X-ray absorption spectroscopy}

$\mathrm{X}$-ray absorption near-edge (XANES) and extended Xray absorption fine structure (EXAFS) spectroscopy was carried out at SSRL beamlines 11-2 and 10-2 using a $\mathrm{Si}$ (2 2 0) double-crystal monochromator. Spectra across the $\mathrm{U} \mathrm{L}_{3}$ electron binding energy edge position were collected in transmission mode. Unreacted cleaned biogenic samples were analyzed in a liquid nitrogen cryostat $(77 \mathrm{~K})$ to improve definition of higher-order shells. Reacted samples (subjected to oxidation in the CFRs) were collected on membrane filters which were analyzed at room temperature. The monochromator was calibrated using an yttrium foil. EXAFS spectra were background-subtracted, splined and analyzed using SIXPack (Webb, 2005). Backscattering phase and amplitude functions required for fitting of spectra were obtained from FEFF 8 (Rehr et al., 1992). The 
uncertainty of the U-oxidation state by XANES spectroscopy is about $10 \%$ for mixtures containing U(IV) and U(VI), based on Singer et al. (2009) and taking into account the lack of knowledge regarding the precise U(VI) species for surface-reacted uraninite.

\subsection{Dissolution rate calculation}

Dissolution rates of the biogenic and chemogenic $\mathrm{UO}_{2}$ materials are derived from the mass balance approach (Eq. (3)) described in Ulrich et al. (2008).

$V \cdot \frac{d[U]_{e f f}}{d t}=Q \cdot[U]_{i n}-Q \cdot[U]_{e f f}+V \cdot R_{d}$

In Eq. (3) $[U]_{\text {eff }}$ and $[U]_{\text {in }}\left(\mathrm{mol} \mathrm{L}^{-1}\right)$ are the $\mathrm{U}$ concentrations in the effluent and influent, $V(\mathrm{~L})$ is the reactor volume, $Q\left(\mathrm{~L} \mathrm{~min}^{-1}\right)$ is the flow rate, and $R_{d}\left(\mathrm{~mol} \mathrm{~L}^{-1}\right.$ $\min ^{-1}$ ) is the rate of $U$ release to solution from $\mathrm{UO}_{2}$ dissolution. Given a constant $R_{d}$ and ideal flow conditions, it takes about five residence times, $\tau=V Q^{-1}$ (min), to achieve steady-state, i.e., $\frac{d[U]_{\text {eff }}}{d t}=0$. Assuming $[U]_{\text {in }}$ is zero, the dissolution rate can be calculated:

$R_{m}=\frac{Q \cdot[U]_{s s}}{V \cdot[\text { solid }]}$

$R_{n}=\frac{Q \cdot[U]_{s s}}{V \cdot S S A \cdot[\text { solid }]}$

where $R_{m}\left(\mathrm{~mol} \mathrm{~g}^{-1} \mathrm{~min}^{-1}\right)$ and $R_{n}\left(\mathrm{~mol} \mathrm{~m}^{-2} \min ^{-1}\right)$ are the dissolution rates normalized to mass and specific surface area, $S S A\left(\mathrm{~m}^{2} \mathrm{~g}^{-1}\right)$, respectively, $[U]_{s s}(\mathrm{~mol} / \mathrm{L})$ is the effluent uranium concentration at steady-state, and [solid $\left(\mathrm{g} \mathrm{L}^{-1}\right)$ is the mass concentration of $\mathrm{UO}_{2}$ in the reactor. The rate calculation accounts for the changes in [solid] and SSA with time, resulting from $\mathrm{UO}_{2}$ dissolution (for details see Ulrich et al., 2008).

To calculate the reaction rate constant, the Gibbs free energy of reaction needs to be considered (Kraemer and Hering, 1997; Lasaga et al., 1994). While the goal was to run the dissolution experiments far from equilibrium, a linear rate law function (Eq. (6)) has been used to account for the distance to equilibrium, where $I A P$ is the ion activity product, and $K_{s p}$ the solubility product with respect to $\mathrm{UO}_{2}$ dissolution under anoxic conditions (Eq. (7)) and with respect to metaschoepite $\left(\mathrm{UO}_{3} \cdot 2 \mathrm{H}_{2} \mathrm{O}\right)$ under oxidizing conditions (Eq. (8)). For the anoxic conditions, the measured equilibrium concentration of dissolved uranium, $[U]_{e q}$, has been used. The predicted $[U]_{e q}$ of metaschoepite was calculated as a function of $[U]_{\text {diss }}, \mathrm{pH}$, and [DIC] using MINEQL+ (Schecher and McAvoy, 1998) and a $\log K_{\text {sp }}$ of 5.39 for the dissolution reaction (Eq. (8)) as suggested by Jang et al. (2006) and Langmuir (1978). The dissolution rate constant $k\left(\mathrm{~mol} \mathrm{~m}^{-2} \mathrm{~min}^{-1}\right)$ for these reactions can then be calculated from Eq. (9).

$$
\begin{aligned}
& f(\Delta G)=\left(1-\frac{I A P}{K_{\mathrm{sp}}}\right) \\
& \mathrm{UO}_{2(\mathrm{~s})}+4 \mathrm{H}^{+} \rightarrow \mathrm{U}^{4+}+2 \mathrm{H}_{2} \mathrm{O} \\
& \mathrm{UO}_{3} \cdot 2 \mathrm{H}_{2} \mathrm{O}_{(\mathrm{s})}+2 \mathrm{H}^{+} \rightarrow \mathrm{UO}_{2}{ }^{2+}+3 \mathrm{H}_{2} \mathrm{O}
\end{aligned}
$$

$$
R_{n}=k \cdot\left(1-\frac{I A P}{K_{\mathrm{sp}}}\right)=k \cdot\left(1-\frac{[U]_{s s}}{[U]_{e q}}\right)
$$

\section{RESULTS}

\subsection{Oxidative $\mathrm{UO}_{2}$ dissolution}

To study the effects of DO on the stability of bio- $\mathrm{UO}_{2}$ and syn- $\mathrm{UO}_{2}$ in aqueous systems, oxygen-free conditions provide the lowest dissolution rates and were applied as the first step of consecutive $\mathrm{UO}_{2+x}$ dissolution (Ulrich et al., 2008). In anoxic, carbonate-free water at $\mathrm{pH}$ $7.5 \pm 0.2$, the dissolved $U$ concentrations in the effluent reached steady-state well below or close to the predicted equilibrium solubility of amorphous $\mathrm{UO}_{2(\mathrm{am})}$ of $3.2 \times$ $10^{-9} \mathrm{M}$ based on the NEA thermodynamic database (Guillaumont et al., 2003). The calculated dissolution rates of both bio- and chemogenic materials were within the same order of magnitude when normalized to surface area, which is consistent with their structural homology (Ulrich et al., 2008). Under reducing conditions, U(VI) was undetectable $\left(<4.2 \times 10^{-10} \mathrm{M}\right)$ in the effluent as verified by KPA. This result suggests that the anoxic $\mathrm{UO}_{2}$ dissolution was primarily driven by hydrolysis of U(IV) and not by oxidation to U(VI) (Eq. (7)).

Even though carbonate is a common groundwater constituent, its aqueous complexes with U(IV) are very weak (Guillaumont et al., 2003) and thus are not expected to change the solubility and dissolution kinetics of $\mathrm{UO}_{2(\mathrm{am})}$ under the experimental conditions. To test this hypothesis, $1 \mathrm{mM}$ DIC was added to the anoxic feed solution as the second step of consecutive $\mathrm{UO}_{2}$ dissolution. Surprisingly, the effluent $[U]_{\text {diss }}$ increased by more than one order of magnitude for the syn- $\mathrm{UO}_{2}$ (Fig. 1c), and about three orders of magnitude for the bio- $\mathrm{UO}_{2}$ (Fig. 1a and b). Whereas the effluent of bio8- $\mathrm{UO}_{2}$ and bio6- $\mathrm{UO}_{2}$ approached a pseudo steady-state $[U]_{\text {diss }}$ between 1 and $5 \mu \mathrm{M}$, the effluent $[U]_{\text {diss }}$ of syn- $\mathrm{UO}_{2}$ peaked at $0.05 \mu \mathrm{M}$ and then continuously diminished toward a steady-state concentration around $0.01 \mu \mathrm{M}$ (Fig. 1c). Roughly the same value has been determined as the experimental equilibrium concentration in the absence of DIC (Ulrich et al., 2008). The dissolution rates of the bio- $\mathrm{UO}_{2}$ were up to 20-times higher than those of the syn- $\mathrm{UO}_{2}$ when normalized to surface area (Table 1). Hence, at least for the bio- $\mathrm{UO}_{2}$, the presence of carbonate considerably accelerated the dissolution process under reducing conditions, which is likely explained by complexation and detachment of a uranium species other than U(IV). Interestingly, effluent analyses by KPA ruled out the possibility of U(VI) mobilization beyond the detection limit of $4.2 \times 10^{-10} \mathrm{M}$.

Step three of the flow-through $\mathrm{UO}_{2+x}$ dissolution experiment showed a change of rate when switching to moderately oxidizing conditions $\left(1 \mathrm{vol} \% P_{\mathrm{O} 2}\right)$ while keeping the $1 \mathrm{mM}$ DIC feed solution. The introduced oxygen dissolved quickly in the feed solution up to a level of $0.4-0.6 \mathrm{mg} / \mathrm{L}$ (Fig. 1d-f), which is consistent with the expected DO equilibrium in water at $20^{\circ} \mathrm{C}$ and 1 bar of gas pressure. The effluent $[U]_{\text {diss }}$ of the syn- $\mathrm{UO}_{2}$ material showed the highest 

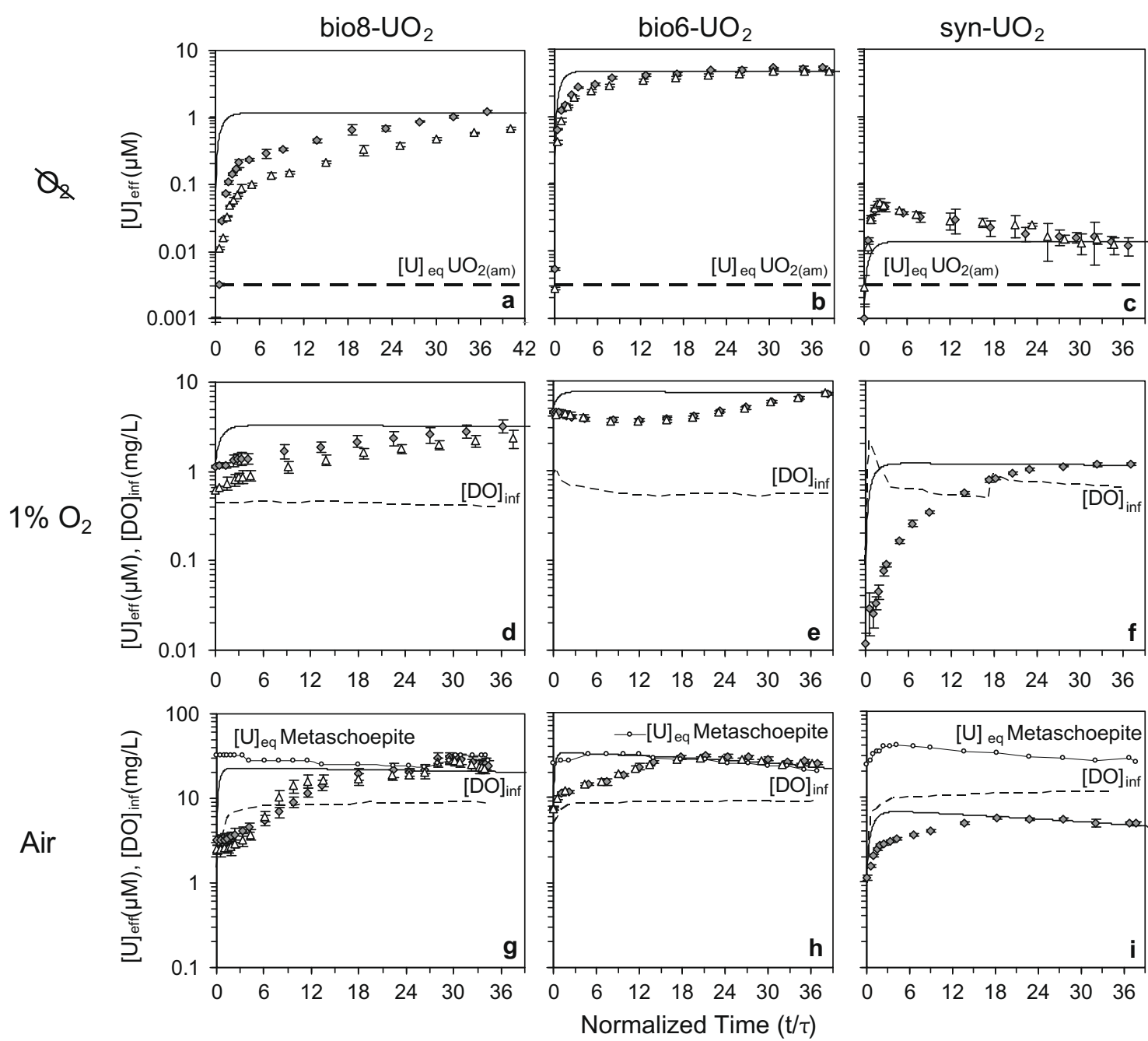

Fig. 1. Flow-through dissolution of bio8- $\mathrm{UO}_{2}(\mathrm{a}, \mathrm{d}, \mathrm{g})$, bio6- $\mathrm{UO}_{2}(\mathrm{~b}, \mathrm{e}, \mathrm{h})$, and syn- $\mathrm{UO}_{2}(\mathrm{c}, \mathrm{f}, \mathrm{i})$ as a function of oxygen concentration in the influent, sequentially raised from reducing atmosphere $\left(5 \mathrm{vol} \% P_{\mathrm{H} 2}, \mathrm{a}-\mathrm{c}\right)$ to $1 \mathrm{vol} \% P_{\mathrm{O} 2}(\mathrm{~d}-\mathrm{f})$ to $21 \mathrm{vol} \% P_{\mathrm{O} 2}\left(\mathrm{~g}-\mathrm{i}\right.$; each gas balanced with $\left.\mathrm{N}_{2}\right)$. The feed solution contained $1 \mathrm{mM}$ DIC at $7.6 \pm 0.1$, effluent $\mathrm{pH}$ was $8.2 \pm 0.3$. Symbols represent effluent concentrations of dissolved $\mathrm{U}$ of two replicate reactors as a function of residence times $(t / \tau$, with $\tau=6-9 \mathrm{~min}$. Error bars reflecting one standard deviation of analysis are mostly smaller than the symbol size. The thin dashed lines show the concentration of dissolved oxygen (DO) monitored in the influent. The thick dashed and the dotted lines indicate the equilibrium concentrations of amorphous $\mathrm{UO}_{2}\left(\log K_{\mathrm{sp}}-1.5\right)$ and metaschoepite, $\mathrm{UO}_{3} \cdot 2 \mathrm{H}_{2} \mathrm{O}$ $\left(\log K_{\mathrm{sp}}-5.39\right)$ calculated from thermodynamic data. The solid line shows the modeled response to $\mathrm{UO}_{2}$ dissolution with rate constants given in Table $1 . \mathrm{UO}_{2}$ dissolution was continued from a flow-through experiment which ran under reducing conditions in the absence of carbonate (see Ulrich et al, 2008).

increase from 0.01 to $1.2 \mu \mathrm{M}$, and appeared to reach steady-state (Fig. 1f). In comparison, the increase of the effluent $[U]_{\text {diss }}$ of the bio- $\mathrm{UO}_{2}$ was more moderate and time-delayed, reflecting only a small acceleration of the dissolution rate upon switching from reducing to moderately oxidizing conditions. Effluent samples analyzed by KPA indicated small fractions of dissolved U(VI) on the order of 5-10\% of $[U]_{\text {diss }}$, demonstrating that at least part of the biogenic $\mathrm{UO}_{2}$ material was fully oxidized from U(IV) to U(VI). Assuming that the effluent concentrations were at steadystate and the final stage of U-oxidation would be metaschoepite, the surface area-normalized dissolution rates and rate constants $(k)$ for the biogenic and chemogenic $\mathrm{UO}_{2}$ materials were of the same order of magnitude and within the range of $1-6 \times 10^{-10} \mathrm{~mol} \mathrm{~m}^{-2} \mathrm{~s}^{-1}$ (Table 1). As already mentioned in Section 2.5, the rate constants were calculated from experimentally measured dissolution rates.

Step four of the flow-through $\mathrm{UO}_{2}$ dissolution tested the change of rate following an increase from a $1 \%$ to a $21 \mathrm{vol} \%$ $P_{\mathrm{O} 2}$ atmosphere in the headspace of a $1 \mathrm{mM}$ DIC feed solution. This change in $P_{\mathrm{O} 2}$ was quickly recorded by the DO probe in the influent, showing $9-10 \mathrm{mg} / \mathrm{L}$ as expected (Fig. 1g-i). In response to the higher DO concentration, the proportion of $\mathrm{U}(\mathrm{VI})$ in the effluent exceeded $80 \%$ of 
Table 1

Comparison of $\mathrm{UO}_{2}$ dissolution rates obtained from flow-through dissolution in $12.6 \mathrm{~mL}$ CFRs under different experimental conditions. $\mathrm{U}$ dissolution rates are based on mass $\left(R_{m}\right)$ or surface area $\left(R_{n}\right)$ of $\mathrm{UO}_{2}$ solids assuming steady-state was reached. The rate constant $k$ accounts for the Gibbs free energy function $f(\Delta G)$, calculated with Eq. (9), Section 2.5. All rates account for the time-dependent loss of material during $\mathrm{UO}_{2}$ dissolution.

\begin{tabular}{|c|c|c|c|c|c|c|c|c|c|c|}
\hline Material & $\begin{array}{l}{[\text { Solid }]} \\
\mathrm{g} / \mathrm{L}\end{array}$ & $\begin{array}{l}\text { Flow rate } \\
\mathrm{mL} / \mathrm{min}\end{array}$ & $\begin{array}{l}P_{\mathrm{O} 2} \\
\text { bar }\end{array}$ & $\begin{array}{l}{[\mathrm{DIC}]} \\
\mathrm{M}\end{array}$ & $\begin{array}{l}\mathrm{pH} \\
-\end{array}$ & $\begin{array}{l}R_{\mathrm{m}} \\
\mathrm{mol} \mathrm{g}^{-1} \mathrm{~s}^{-1}\end{array}$ & $\begin{array}{l}R_{\mathrm{n}} \\
\mathrm{mol} \mathrm{m}^{-2} \mathrm{~s}^{-1}\end{array}$ & $\begin{array}{l}f(\Delta \mathrm{G}) \\
-\end{array}$ & $\begin{array}{l}k \\
\mathrm{~mol} \mathrm{~m}^{-2} \mathrm{~s}^{-1}\end{array}$ & $\operatorname{Ref}^{a}$ \\
\hline \multicolumn{11}{|c|}{ This work, anoxic conditions } \\
\hline Bio6- $\mathrm{UO}_{2}$ & 1.15 & 1.42 & $<10^{-6}$ & $10^{-3}$ & 8.57 & $8.35 \times 10^{-09}$ & $1.64 \times 10^{-10}$ & 0.896 & $1.83 \times 10^{-10}$ & \\
\hline Bio8- $\mathrm{UO}_{2}$ & 1.60 & 2.02 & $<10^{-6}$ & $10^{-3}$ & 8.58 & $1.52 \times 10^{-09}$ & $3.03 \times 10^{-11}$ & 0.968 & $3.13 \times 10^{-11}$ & \\
\hline Syn- $\mathrm{UO}_{2}$ & 0.79 & 1.97 & $<10^{-6}$ & $10^{-3}$ & 8.64 & $4.86 \times 10^{-11}$ & $8.56 \times 10^{-12}$ & 0.997 & $8.58 \times 10^{-12}$ & \\
\hline \multicolumn{11}{|c|}{ This work, moderately oxidizing conditions } \\
\hline Bio6-UO ${ }_{2}$ & 1.73 & 1.87 & 0.01 & 0 & 8.58 & $6.63 \times 10^{-11}$ & $1.32 \times 10^{-12}$ & 0.836 & $1.58 \times 10^{-12}$ & \\
\hline Syn-UO ${ }_{2}$ & 1.23 & 1.81 & 0.01 & 0 & 8.51 & $2.36 \times 10^{-11}$ & $3.98 \times 10^{-12}$ & 0.920 & $4.33 \times 10^{-12}$ & \\
\hline Bio6-UO $\mathrm{UO}_{2}$ & 1.73 & 2.01 & 0.01 & $10^{-4}$ & 8.22 & $2.30 \times 10^{-09}$ & $4.57 \times 10^{-11}$ & 0.915 & $5.00 \times 10^{-11}$ & \\
\hline Syn- $\mathrm{UO}_{2}$ & 1.23 & 1.89 & 0.01 & $10^{-4}$ & 8.20 & $1.16 \times 10^{-09}$ & $1.95 \times 10^{-10}$ & 0.991 & $1.97 \times 10^{-10}$ & \\
\hline Bio6- $\mathrm{UO}_{2}$ & 1.10 & 1.18 & 0.01 & $10^{-3}$ & 8.17 & $1.19 \times 10^{-08}$ & $2.27 \times 10^{-10}$ & 0.850 & $2.67 \times 10^{-10}$ & \\
\hline Bio6-UO $\mathrm{UO}_{2}$ & 1.66 & 1.96 & 0.01 & $10^{-3}$ & 8.51 & $1.47 \times 10^{-08}$ & $2.88 \times 10^{-10}$ & 0.844 & $3.42 \times 10^{-10}$ & \\
\hline Bio8-UO $\mathrm{UO}_{2}$ & 1.59 & 1.96 & 0.01 & $10^{-3}$ & 7.90 & $4.67 \times 10^{-09}$ & $9.25 \times 10^{-11}$ & 0.940 & $9.83 \times 10^{-11}$ & \\
\hline Syn- $\mathrm{UO}_{2}$ & 0.79 & 1.91 & 0.01 & $10^{-3}$ & 8.00 & $3.94 \times 10^{-09}$ & $6.62 \times 10^{-10}$ & 0.993 & $6.67 \times 10^{-10}$ & \\
\hline Syn- $\mathrm{UO}_{2}$ & 1.21 & 1.98 & 0.01 & $10^{-3}$ & 8.58 & $3.35 \times 10^{-09}$ & $5.63 \times 10^{-10}$ & 0.979 & $5.75 \times 10^{-10}$ & \\
\hline Bio6-UO ${ }_{2}$ & 1.23 & 1.19 & 0.01 & $10^{-2}$ & 8.79 & $2.53 \times 10^{-08}$ & $4.78 \times 10^{-10}$ & 0.989 & $4.83 \times 10^{-10}$ & \\
\hline Syn- $\mathrm{UO}_{2}$ & 1.14 & 1.97 & 0.01 & $10^{-2}$ & 8.71 & $1.50 \times 10^{-09}$ & $2.50 \times 10^{-10}$ & 0.985 & $2.54 \times 10^{-10}$ & \\
\hline \multicolumn{11}{|c|}{ This work, strongly oxidizing conditions } \\
\hline Bio6-UO ${ }_{2}$ & 1.00 & 1.19 & 0.21 & $10^{-3}$ & 8.25 & $7.43 \times 10^{-08}$ & $1.02 \cdot 10^{-09}$ & 0.407 & $2.50 \cdot 10^{-09}$ & \\
\hline $\mathrm{Bio} 8-\mathrm{UO}_{2}$ & 1.56 & 1.78 & 0.21 & $10^{-3}$ & 8.10 & $5.08 \times 10^{-08}$ & $9.06 \cdot 10^{-10}$ & 0.604 & $1.50 \cdot 10^{-09}$ & \\
\hline Syn- $\mathrm{UO}_{2}$ & 0.75 & 1.95 & 0.21 & $10^{-3}$ & 8.00 & $2.97 \times 10^{-08}$ & $4.84 \cdot 10^{-09}$ & 0.908 & $5.33 \cdot 10^{-09}$ & \\
\hline \multicolumn{11}{|c|}{ Published data, oxidizing conditions } \\
\hline $\mathrm{UO}_{2}$ pellets & $1.0 \mathrm{~g}^{\mathrm{b}}$ & 0.10 & 0.05 & 0 & 8.0 & & $3.89 \cdot 10^{-12}$ & & & 1 \\
\hline $\mathrm{UO}_{2}$ pellets & $1.0 \mathrm{~g}^{\mathrm{b}}$ & 0.10 & 0.05 & 0 & 6.5 & & $4.86 \cdot 10^{-12}$ & & & 1 \\
\hline $\mathrm{UO}_{2}$ pellets & & Batch & 0.20 & 0 & 7.0 & & $1.06 \cdot 10^{-11}$ & & & 2 \\
\hline Syn-UO ${ }_{2(\mathrm{cr})}$ & & $0.004-0.08$ & 0.21 & $10^{-3}$ & 8.0 & & $1.00 \cdot 10^{-10}$ & & & 3 \\
\hline $\mathrm{UO}_{2}$ pellets & & unknown & 0.21 & $10^{-2}$ & 8.5 & & $1.60 \cdot 10^{-10}$ & & & 4 \\
\hline Syn-UO ${ }_{2}$ & $0.1 \mathrm{~g}^{\mathrm{b}}$ & 0.10 & 0.21 & 0 & 8.6 & & $8.27 \cdot 10^{-12}$ & & & 5 \\
\hline Syn- $\mathrm{UO}_{2}$ & $0.1 \mathrm{~g}^{\mathrm{b}}$ & 0.19 & 0.21 & $10^{-2}$ & 8.4 & & $1.60 \cdot 10^{-10}$ & & & 5 \\
\hline
\end{tabular}

${ }^{a}$ References: (1) Casas et al. (1994), (2) Thomas and Till (1984), (3) Pierce et al. (2005), (4) De Pablo et al. (1996), (5) Bruno et al. (1995). Data are from the present work if no reference is given.

${ }^{\mathrm{b}}$ A thin film was used in this work.

$[U]_{\text {diss. }}$ While the steady-state concentration of both biogenic $\mathrm{UO}_{2}$ materials approached the calculated equilibrium concentration of metaschoepite, the effluent concentration from chemogenic $\mathrm{UO}_{2}$ dissolution stayed below equilibrium. Nevertheless, the calculated dissolution rate constants normalized to surface area were close to one another, ranging from 1.5 to $5.3 \times 10^{-9} \mathrm{~mol} \mathrm{~m}^{-2} \mathrm{~s}^{-1}$ (Table 1). Potential explanations for this behavior are discussed below in Section 4.3.

\subsection{Effect of carbonate on $\mathrm{UO}_{2+x}$ dissolution under moderately oxidizing conditions}

The results shown in the previous section demonstrate that carbonate promotes the dissolution of biogenic $\mathrm{UO}_{2}$ under reducing conditions. Likewise, the dissolution rates are dependent on [DO], an effect which has been studied at a constant concentration of $1 \mathrm{mM}$ DIC. The following experiment investigated the effect of carbonate on $\mathrm{UO}_{2}$ dissolution under moderately oxidizing conditions. While maintaining a $1 \mathrm{vol} \% P_{\mathrm{O} 2}$ headspace in the feed solution, the $[\mathrm{DIC}]$ was raised step-wise from zero to $0.1,1.0$, and
$10 \mathrm{mM}$ by adding the equivalent amount of $\mathrm{NaHCO}_{3}$. In Fig. 2, the effluent $[U]_{\text {diss }}$ of bio6-UO $\mathrm{U}_{2}$ (Fig. $2 \mathrm{a}$ and c) and syn- $\mathrm{UO}_{2}$ (Fig. 2b and d) are compared for duplicate runs at each condition. In the absence of DIC, the effluent $[U]_{\text {diss }}$ steadily increased without reaching a steady-state within $\sim 40$ residence times $(t / \tau)$. Hence, the dissolution process accelerated with time, and the highest rates recorded from this period amount to $1.3 \times 10^{-12}$ and $4.0 \times 10^{-12} \mathrm{~mol}$ $\mathrm{m}^{-2} \mathrm{~s}^{-1}$ for the biogenic and the chemogenic $\mathrm{UO}_{2}$, respectively (Table 1). Upon the addition of $0.1 \mathrm{mM} \mathrm{DIC,} \mathrm{with}$ the exception of one bio- $\mathrm{UO}_{2}$ replicate, the effluent $[U]_{\text {diss }}$ yielded a transient peak and quickly approached a pseudo steady-state concentration of $0.5-0.6 \mu \mathrm{M}$ for syn- $\mathrm{UO}_{2}$ and $1.0-1.6 \mu \mathrm{M}$ for bio- $\mathrm{UO}_{2}$ (Fig. $2 \mathrm{a}$ and b). The surface area-normalized average dissolution rates were $4.6 \times$ $10^{-11}$ and $2.0 \times 10^{-10} \mathrm{~mol} \mathrm{~m}^{-2} \mathrm{~s}^{-1}$ for the biogenic and the chemogenic $\mathrm{UO}_{2}$, demonstrating a dissolution-promoting effect of carbonate and a higher dissolution rate constant for the chemogenic material.

After increasing the DIC in the feed solution to $1 \mathrm{mM}$, the effluent $[U]_{\text {diss }}$ increased slightly for the chemogenic and considerably for the biogenic $\mathrm{UO}_{2}$, reaching a steady- 

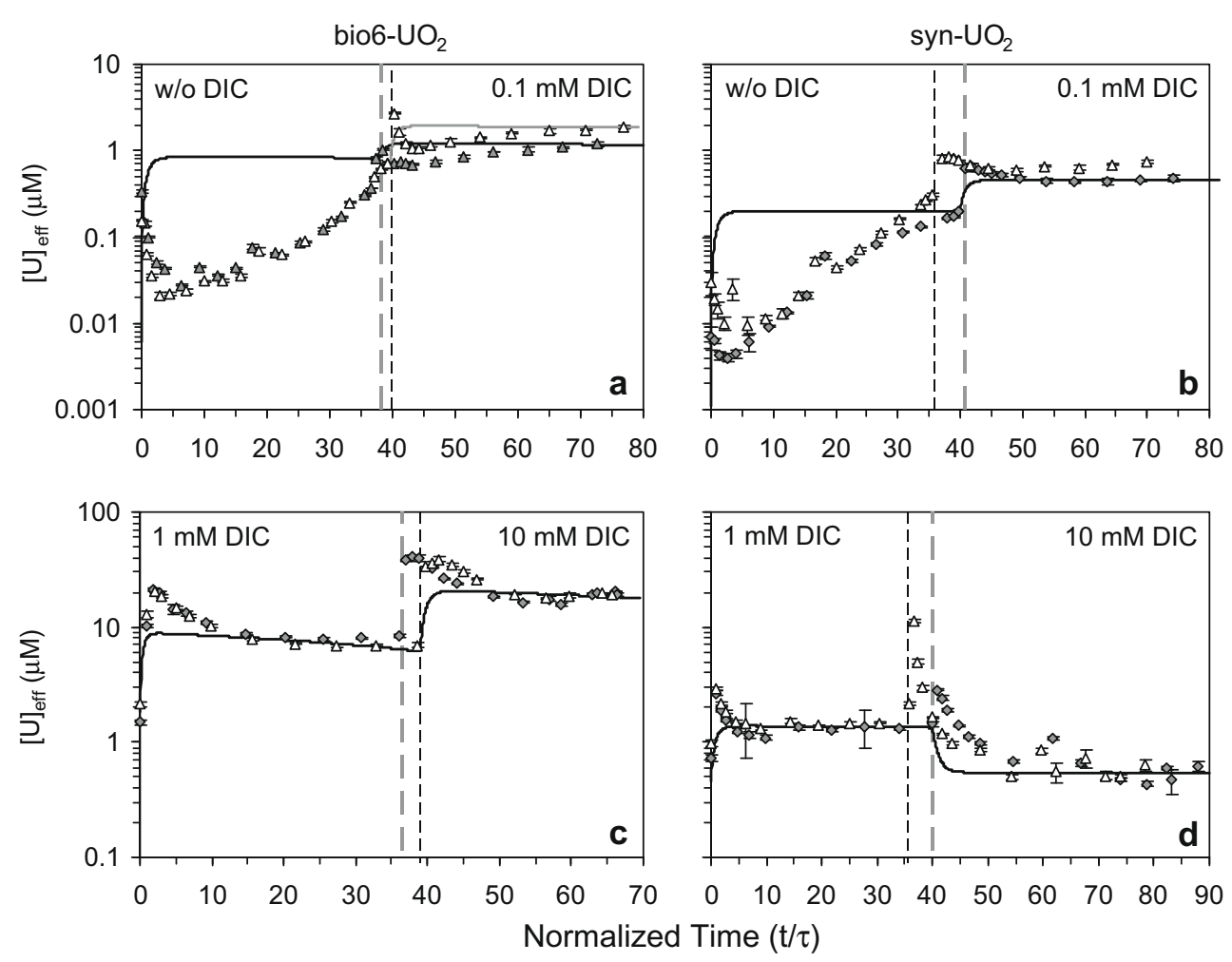

Fig. 2. Flow-through dissolution of bio6- $-\mathrm{UO}_{2}$ (a and c) and syn- $\mathrm{UO}_{2}$ (b and d) as a function of DIC concentration in the feed solution, sequentially raised from 0 to 0.1 ( $a$ and $b$ ) and to 1.0 and $10 \mathrm{mM}$ DIC ( $c$ and d); vertical dashed lines indicate the switch of experimental conditions for each reactor. The feed solution was equilibrated with $1 \mathrm{vol} \% P_{\mathrm{O} 2}$ and $99 \mathrm{vol} \% P_{\mathrm{N} 2}$. Symbols represent effluent concentrations of dissolved $\mathrm{U}$ of two replicate reactors as a function of residence times $(t / \tau$, with $\tau=6-10 \mathrm{~min})$. Error bars reflecting one standard deviation of analysis are mostly smaller than the symbol size. The effluent $\mathrm{pH}$ was $8.5 \pm 0.4$. The solid line shows the modeled response to $\mathrm{UO}_{2}$ dissolution with rate constants given in Table 1 .

state of 1.5 and $7 \mu \mathrm{M}$, respectively (Fig. $2 \mathrm{c}$ and d). The surface area-normalized dissolution rates yielded $2.9 \times 10^{-10}$ and $5.6 \times 10^{-10} \mathrm{~mol} \mathrm{~m}^{-2} \mathrm{~s}^{-1}$ and thus were consistent with the rates determined from the aforementioned dissolution experiment carried out at the same [DIC] and $P_{\mathrm{O} 2}$ conditions (Table 1). After further increasing the influent [DIC] to $10 \mathrm{mM}$, the effluent $[U]_{\text {diss }}$ of the bio- $\mathrm{UO}_{2}$ material showed another step-increase and leveled off at a higher steady-state concentration compared to the preceding condition (Fig. 2c). In contrast, for the syn- $\mathrm{UO}_{2}$ a transient $[U]_{\text {diss }}$ peak was followed by a slightly lower steady-state level than during the preceding condition (Fig. 1d). The surface area-normalized dissolution rate constants $(k)$ of the bio- and chemogenic $\mathrm{UO}_{2}$ were very close to one another, $4.8 \times 10^{-10}$ and $2.5 \times 10^{-10} \mathrm{~mol} \mathrm{U} \mathrm{m}{ }^{-2} \mathrm{~s}^{-1}$, consistent with the structural homology of both materials (see Section 4.3.).

\subsection{Effects of intermittent oxygen or carbonate supply on $\mathrm{UO}_{2+x}$ dissolution}

Both carbonate and DO accelerated the dissolution of the bio- and chemogenic $\mathrm{UO}_{2}$. To study the reversibility of each dissolution process individually, the syn- $\mathrm{UO}_{2}$ material was first reacted under carbonate-free reducing conditions and then intermittently treated with either $1 \mathrm{mM}$
DIC or 1 vol $\% P_{\mathrm{O} 2}$ before re-establishing the initial condition. After adding $1 \mathrm{mM}$ DIC, the effluent $[U]_{\text {diss }}$ linearly increased indicating that carbonate gradually made the $\mathrm{UO}_{2}$ surface more susceptible to dissolution (Fig. 3a). If the intrinsic rate of $\mathrm{UO}_{2}$ dissolution was unaffected by carbonate, the effluent $[U]_{\text {diss }}$ would have stayed unchanged as represented by the dashed line. In contrast, an instantaneous increase of the dissolution rate constant would have resulted in a $[U]_{\text {diss }}$ curve as shown by the black line. When the influent was switched back to DIC-free water, however, the effluent $[U]_{\text {diss }}$ dropped to the preceding concentration level within five residence times, which is consistent with an immediate relapse of the dissolution rate to the preceding value and a washout of excess $[U]_{\text {diss }}$ that was consistent with the behavior of a conservative solute in a CFR as demonstrated by the model (black line). This result shows that the promoting effect of carbonate on $\mathrm{UO}_{2}$ dissolution was fully reversible.

After switching from reducing to oxidizing conditions, provided by a $1 \mathrm{vol} \% P_{\mathrm{O} 2}$ atmosphere in the influent, the effluent $[U]_{\text {diss }}$ increased and approached a steady-state of $\sim 1 \mu \mathrm{M}$ after 14 residence times (Fig. 3b). After reintroducing the anoxic influent, the effluent $[U]_{\text {diss }}$ level stayed the same over the subsequent 20 residence times. This result shows that the oxidative dissolution process was not immediately reversible. 

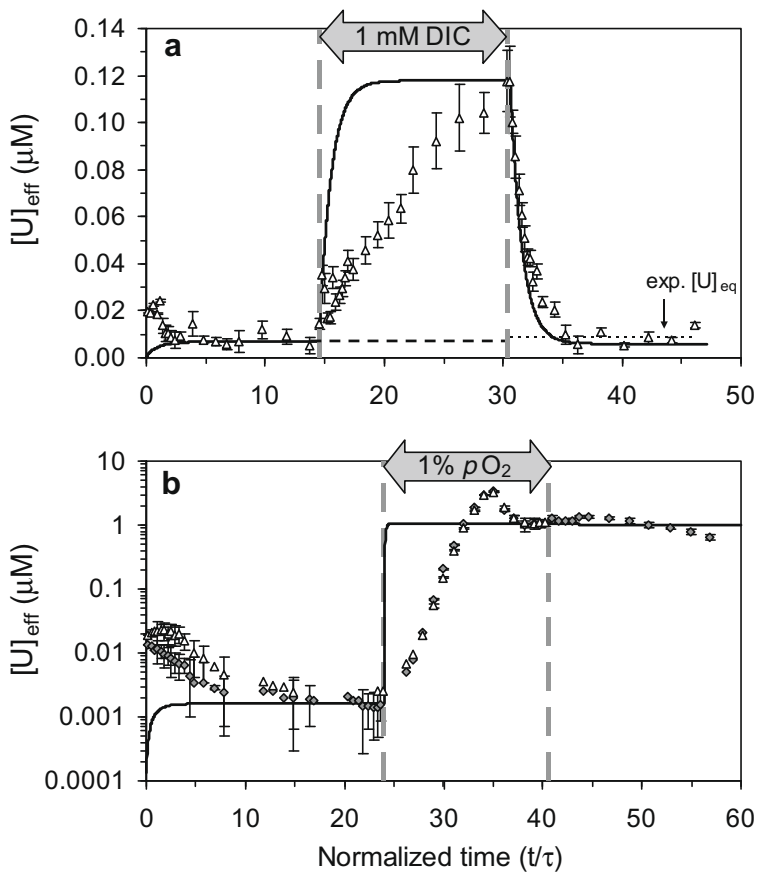

Fig. 3. Effect of intermittent feed of (a) $1 \mathrm{mM}$ DIC, and (b) $1 \mathrm{vol} \%$ $P_{\mathrm{O} 2}$ on the flow-through dissolution of syn- $\mathrm{UO}_{2}$ at $\mathrm{pH}$ 8.0-8.3 (a) and $\mathrm{pH} \sim 7.5$ (b) under otherwise reducing conditions; vertical dashed lines indicate the switch of experimental conditions. Symbols show the effluent concentrations of dissolved uranium as a function of residence times ( $\tau=12-15 \mathrm{~min}$ ). Error bars reflecting one standard deviation of analysis are sometimes smaller than the symbol size. The solid line shows the modeled response to a step-function change in $\mathrm{UO}_{2}$ dissolution with rate constants of (a) $1.3 \times 10^{-11}, 6.3 \times 10^{-11}$, and $1.3 \times 10^{-11} \mathrm{~mol} \mathrm{U} \mathrm{m}^{-2} \mathrm{~s}^{-1}$, and (b) $4.2 \times 10^{-13}$ and $1.7 \times 10^{-9} \mathrm{~mol} \mathrm{U} \mathrm{m}^{-2} \mathrm{~s}^{-1}$. If carbonate had no effect, $[U]_{\mathrm{eff}}$ should follow the dashed steady-state line. The dotted line visualizes the experimentally determined equilibrium concentration.

\subsection{XAS and XPS spectroscopic analyses of $\mathrm{UO}_{2+x}$}

\subsubsection{X-ray absorption spectroscopy}

XANES and EXAFS spectra for key samples are shown in Fig. 4 and compared to reference spectra for stoichiometric $\mathrm{UO}_{2.00}$ (uncorroded uraninite) as well as $\mathrm{UO}_{2.20}$ and $\mathrm{UO}_{2.25}\left(\mathrm{U}_{4} \mathrm{O}_{9}\right)$ obtained from Conradson et al. (2005, 2004). Initial fits to the XANES data were performed using linear combinations of stoichiometric $\mathrm{UO}_{2.0}$ and crystalline uranyl nitrate. This model assumes that all higher-valent $\mathrm{U}$ is present in the samples exclusively as $\mathrm{UO}_{2}{ }^{2+}$, for which the formal uranium oxidation state is $+\mathrm{VI}$ and has the specific transdioxo uranyl cation structure. This model is not appropriate for samples containing $\mathrm{UO}_{2+x}$, where the predominant $\mathrm{U}$ site local structure is believed to be more similar to that in $\mathrm{UO}_{2.0}$, and the oxidation state is likely to vary between $+\mathrm{IV}$ and $+\mathrm{V}$, and possibly even as high as $+\mathrm{VI}$ (vide infra). In particular, we note that a $\mathrm{UO}_{2} /$ uranyl XANES fitting model may not detect even moderate concentrations of higher-valent uranium such as $\mathrm{U}^{\mathrm{V}+}$, particularly if it occupies a uranium lattice site in $\mathrm{UO}_{2+x}$, due to the possible similarity between the XANES for $\mathrm{U}^{\mathrm{VI}+}$ and $\mathrm{U}^{\mathrm{V}+}$ on the same site. Therefore, in the case where $\mathrm{UO}_{2+x}$ is likely to be important, the most appropriate XANES model spectra are those for $\mathrm{UO}_{2.0}$ and $\mathrm{UO}_{2.25}$ $\left(\mathrm{U}_{4} \mathrm{O}_{9}\right)$, which are likely end-members to be encountered under groundwater conditions. XANES fits to all samples, except that from the $21 \% P_{\mathrm{O} 2}$ SBR experiment, yielded $100 \% \mathrm{UO}_{2}$ regardless of the XANES model used, implying that the average uranium oxidation in the bulk of the samples was $+\mathrm{IV}$ within the detection limit of $5-10 \% \mathrm{UO}_{2.25}$ or uranyl. Fits to the $21 \% P_{\mathrm{O} 2} \mathrm{SBR}$ sample, believed to be $\mathrm{UO}_{2+x}$ (vide infra) yielded $80 \pm 10 \% \mathrm{UO}_{2.25}$ and the balance $\mathrm{UO}_{2.00}$ (Fig. 4a), yielding an overall bulk stoichiometry of

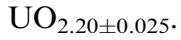
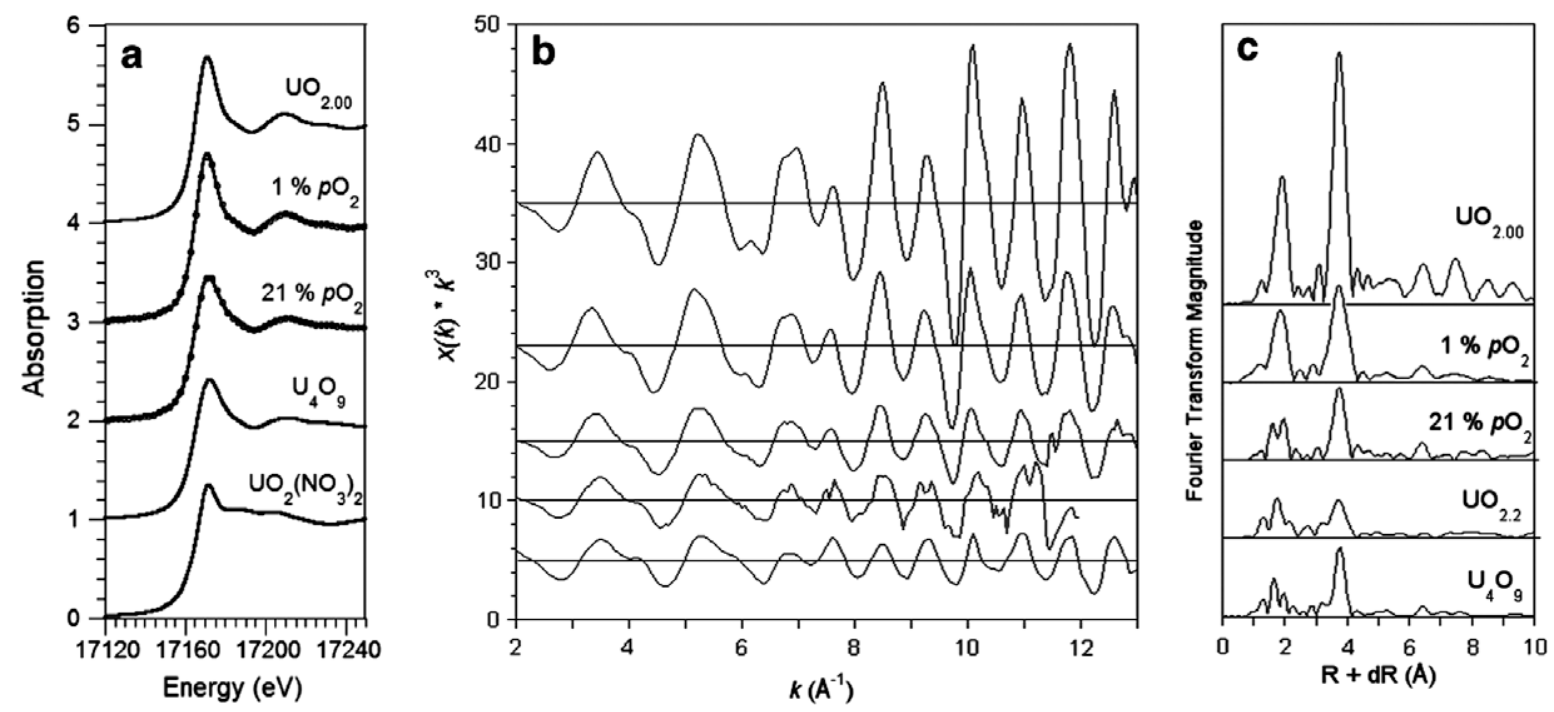

Fig. 4. (a) Uranium $\mathrm{L}_{3}$ edge XANES spectra, (b) $\mathrm{k}^{3}$ weighted EXAFS spectra and (c) corresponding Fourier transform magnitude of unreacted, stoichiometric $\mathrm{UO}_{2.00}$ (serving as $\mathrm{U}(\mathrm{IV})$ reference), syn- $\mathrm{UO}_{2}$ residue after treatment in a CFR under moderately oxidizing conditions $\left(1 \% P_{\mathrm{O} 2}\right)$, syn- $\mathrm{UO}_{2}$ residue after treatment in a SBR under strongly oxidizing conditions $\left(21 \% P_{\mathrm{O} 2}\right)$, and standards of $\mathrm{UO}_{2.20}$ (plot $\mathrm{b}$ and c), $\mathrm{U}_{4} \mathrm{O}_{9}$, and crystalline uranyl(VI) nitrate $\left(\mathrm{UO}_{2}\left(\mathrm{NO}_{3}\right)_{2}\right.$, plot a). Solid lines represent experimental data, dotted lines show the fits. 
As shown in Fig. 4, the EXAFS spectra and corresponding Fourier transforms for the $1 \% P_{\mathrm{O} 2} \mathrm{CFR}$ sample are qualitatively similar to that of stoichiometric $\mathrm{UO}_{2.0}$. Both show characteristic FT peaks for the shell of oxygen neighbors at $2.35 \AA$ and next-nearest U neighbors at $3.87 \AA$ (corresponding to FT peaks at $c a 1.8$ and $3.8 \AA, \mathrm{R}+\mathrm{dR}$, respectively). Some differences are apparent between the spectra. In particular, the relative height of the $3.8 \AA \mathrm{U}$ peak is reduced as compared to that of bulk $\mathrm{UO}_{2}$, and the FT peaks above $5 \AA(\mathrm{R}+\mathrm{dR})$, which indicate the extent of intermediate-range order in the material, are attenuated or lost. These observations indicate that, after dissolution, the average uranium environment in the samples has become disordered as compared to unreacted $\mathrm{UO}_{2.0}$.

The EXAFS spectrum for the $21 \% P_{\mathrm{O} 2}$ SBR sample differs considerably from that of $\mathrm{UO}_{2.0}$ and the $1 \% P_{\mathrm{O} 2} \mathrm{CFR}$ sample. In particular, the FT peak corresponding to the $2.35 \AA \mathrm{O}$-shell is sharply diminished. Moreover, there is no O-peak present at ca $1.5 \AA(\mathrm{R}+\mathrm{dR})$, which would be characteristic of uranyl. From these observations it can be concluded that dissolution in air-equilibrated water results in substantial disordering of the local coordination environment around $\mathrm{U}$ but without significant accumulation of uranyl $\left(\mathrm{UO}_{2}{ }^{2+}\right)$. If uranyl was present, then it represented less than $\mathrm{ca} 10 \%$ of the total. The specific modification of the spectrum observed here is characteristic of conversion of $\mathrm{UO}_{2.0}$ to $\mathrm{UO}_{2+x}$ (Conradson et al., 2004). As shown in Fig. 4, the $21 \% P_{\mathrm{O} 2} \mathrm{SBR}$ spectrum is similar to that of $\mathrm{UO}_{2.20}$ (the average composition as determined by XANES) and even more similar to that of $\mathrm{U}_{4} \mathrm{O}_{9}$. These observations indicate that dissolution in air-equilibrated water has resulted in the conversion of $\mathrm{UO}_{2.0}$ to $\mathrm{UO}_{2+x}$, with a composition of the final material between $\mathrm{UO}_{2.20}$ and $\mathrm{UO}_{2.25}$ as suggested by XANES and EXAFS combined.

Conradson et al. (2004) suggested that $\mathrm{UO}_{2+x}$ may contain small quantities of uranyl (up to $c a 15 \%$ of total $\mathrm{U}$ in $\mathrm{UO}_{2.20}$ and $\mathrm{U}_{4} \mathrm{O}_{9}$ ) as part of a separate phase exsolved within the $\mathrm{UO}_{2}$ matrix. If uranyl were present in this form in the samples, then it would occur at or below the detection limit of the present qualitative EXAFS interpretation. To investigate the presence and role of higher valence states of uranium, XPS measurements were performed, as described in the next section.

\subsubsection{X-ray photoelectron spectroscopy}

The original unreacted syn- $\mathrm{UO}_{2}$ material was analyzed by XPS to determine the near-surface stoichiometry and test whether the surface was oxidized. Several lines of evidence suggest that the surfaces of this material were not oxidized within the detection limit of XPS $(\sim 5 \% \mathrm{U}(\mathrm{VI})$ or $\mathrm{U}(\mathrm{V})$, Fig. 5a). First, the FWHM values of the primary peaks (i.e., $\mathrm{U} 4 f_{7 / 2}$ at $380.16 \mathrm{eV}$ for $\mathrm{C} 1 \mathrm{~s}$ at $285.0 \mathrm{eV}$ ) are among the lowest reported in the literature, where the FWHM of $\mathrm{U} 4 f_{7 / 2}$ is $1.43 \mathrm{eV}$. Despite excellent energy resolution, the primary peaks are largely symmetrical with no detectable shoulders or inflection points. The primary peak envelopes required a second small peak at slightly higher binding energy to optimize the final fit. Nonetheless, this slight asymmetry can be attributed to manifest multiplet splitting, not a second component, as suggested by ab initio simulations of the U4 $f$ XPS spectrum for $\mathrm{UO}_{2}$ (Ilton and Bagus, 2008). Second, the spin orbit splitting (10.8 eV), and binding energy separation $(6.96 \mathrm{eV})$ between the satellites and their corresponding primary peaks are close to literature values for stoichiometric $\mathrm{UO}_{2.00}$. This last parameter is a sensitive monitor of non-stoichiometry, as even minor oxidation can significantly decrease this separation (personal observation, ESI). Further, the satellite structures (shape, position, and intensity) are also typical of stoichiometric $\mathrm{UO}_{2.00}$. In particular, there is no indication of the $\mathrm{U}(\mathrm{V})$ satellite that appears at about $1.5 \mathrm{eV}$ above the U(IV) satellite. Finally, the spectra did not vary even after several hours of intense X-ray exposure in the XPS. This is important because $\mathrm{U}(\mathrm{VI})$ and $\mathrm{U}(\mathrm{V})$ were found to be reducible under the conditions used (Ilton et al., 2007).

The XPS result of the unreacted syn- $\mathrm{UO}_{2}$ is consistent with EXAFS spectra, which did not show evidence of $\mathrm{U}(\mathrm{VI})$ based on the detection limit of up to $10 \%$-mass. However, the XPS results of uncleaned original bio8 $-\mathrm{UO}_{2}$ and bio6- $\mathrm{UO}_{2}$ materials indicated small but measurable apparent non-stoichiometry (Table 2). Some proportion of this apparent non-stoichiometry might be due to oxidized $U$ sorbed to the biomass matrix. If so, this signal would be amplified relative to the signal originating from the nanoparticulate $\mathrm{UO}_{2}$ due to the surface sensitivity of XPS. Indeed, XANES spectroscopy did not detect any uranyl components in the nano-biogenic $\mathrm{UO}_{2}$ (Schofield et al., 2008), although these authors pointed out that non-uranyl forms of $\mathrm{U}^{\mathrm{V}+}$ and $\mathrm{U}^{\mathrm{VI}+}$ could not be ruled out. In contrast, XPS analyses of biogenic $\mathrm{UO}_{2}$ washed with anoxic $\mathrm{NaOH}$ solutions recorded significant increases in the proportion of U(V) at the expense of U(IV) (Table 2). This observation suggests partial pre-oxidation near the surface of the cleaned bio- $\mathrm{UO}_{2}$ that confounded the concomitant XPS analysis of the dissolution study. Hence, the dissolution and transformation of syn- $\mathrm{UO}_{2}$ will be the focus of the remaining spectroscopic results and discussion.

After partial dissolution of the syn- $\mathrm{UO}_{2}$ powder in anoxic water at near-neutral $\mathrm{pH}$ (2 replicates), the surface of the residual solid exhibited about $18-21 \%$ of $\mathrm{U}(\mathrm{V})$ and $7-$ $10 \%$ of U(VI), as shown by XPS (Table 2). Similar results were found after treatment at $\mathrm{pH} 2$. As there is no significant difference among these results, a representative spectrum is shown in Fig. 5b. While maintaining anoxic conditions and treating the material with a $1 \mathrm{mM}$ DIC solution at $\mathrm{pH} 8.5$, the proportion of $\mathrm{U}(\mathrm{VI})$ on the surface did not change significantly. Although the proportion of $\mathrm{U}(\mathrm{V})$ diminished to $14 \%$, this difference is not significant either, given the estimated relative uncertainties of $\pm 25-30 \%$ and $\pm 7 \%$ for $\sim 0.1-0.2$ and $\sim 0.7$ mole fraction components, respectively. When applying moderately oxidizing conditions $\left(1 \%\right.$ vol $\left.P_{\mathrm{O} 2}\right)$ in the absence of DIC, the proportions of $\mathrm{U}(\mathrm{V})$ and $\mathrm{U}(\mathrm{VI})$ on the $\mathrm{UO}_{2}$ surface increased to $28 \%$ and $17 \%$, respectively (Fig. 5c). However, XANES spectra of the syn- $\mathrm{UO}_{2}$ residues reacted under reducing (data not shown) and moderately oxidizing conditions (Fig. 4a) consistently showed $100 \% \mathrm{U}(\mathrm{IV})$, ruling out substantial oxidation in the bulk of the reacted materials. This is corroborated by the EXAFS results. 


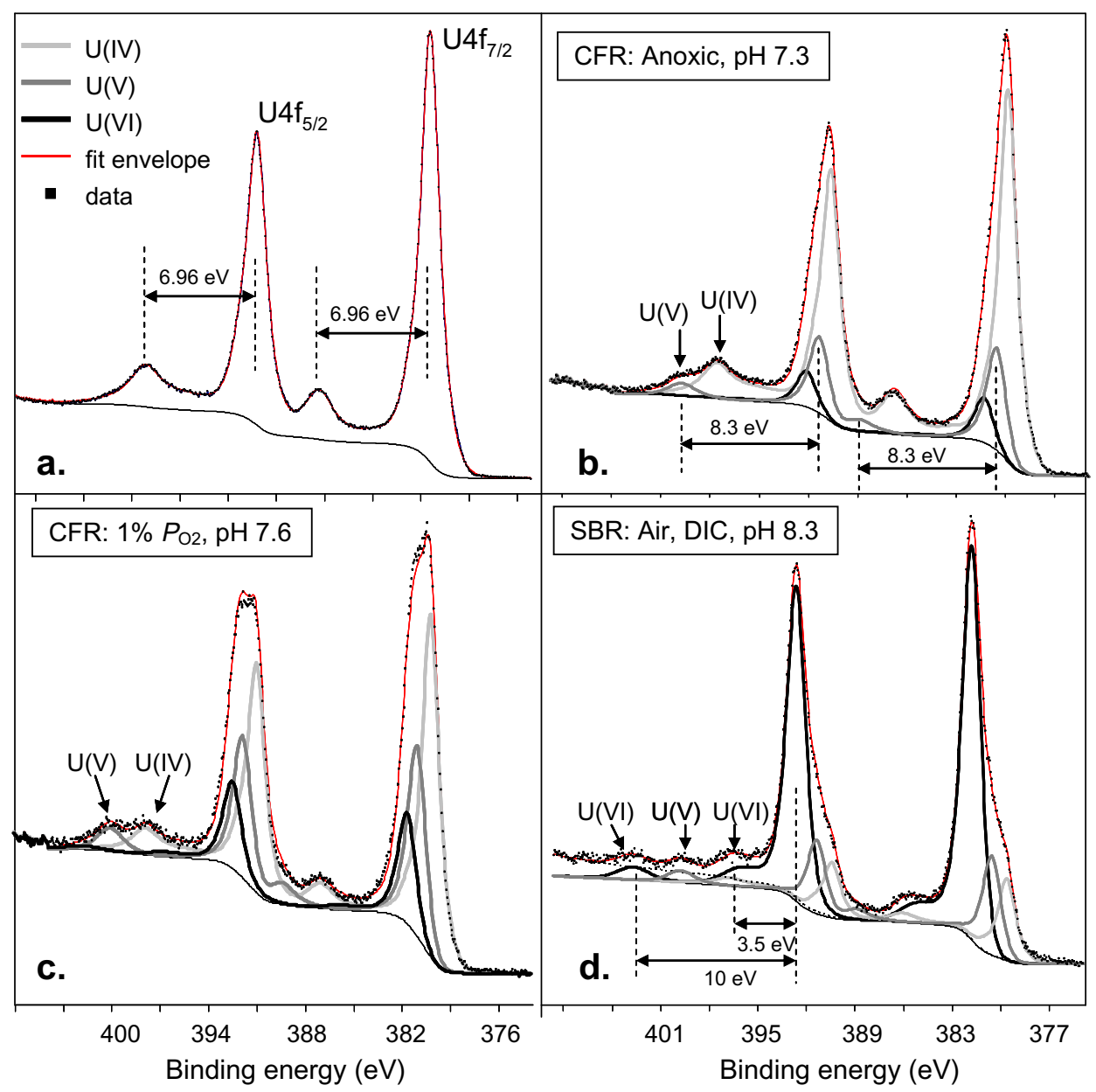

Fig. 5. Deconvolution of four representative XPS spectra of chemogenic $\mathrm{UO}_{2+x}$ : Original unreacted $\mathrm{UO}_{2.0}$ material (a) and after partial dissolution in the absence of carbonate in a CFR experiment under anoxic conditions at $\mathrm{pH} 7.3$ (b) and under mildly oxidizing conditions ( $1 \%$ $P_{\mathrm{O} 2}$ ) at $\mathrm{pH} 7.6$ (c). Material from an SBR experiment carried out under strongly oxidizing conditions (air) in $1 \mathrm{mM}$ DIC solution at pH 8.3 (d).

After partial dissolution of the syn- $\mathrm{UO}_{2}$ material in airequilibrated water $\left(21 \%\right.$ vol $\left.P_{\mathrm{O} 2}\right)$ containing $1 \mathrm{mM}$ DIC, the XPS-detectable U(VI) fraction increased considerably to $44 \%$ in the CFR setup, and to $68 \%$ in the SBR experiment (Fig. 5d, Table 2), whereas the U(IV):U(V) ratios were close to 1 in both experiments. The EXAFS results did not support the presence of the short axial $\mathrm{U}=\mathrm{O}$ bond (i.e., $\sim 1.8 \AA$ ) typical of uranyl (V or VI), implying that the oxidized U identified by XANES primarily exists on uraninite lattice sites as charge defects. XPS results for U(V) and $\mathrm{U}(\mathrm{IV})$ yield a stoichiometry of $\mathrm{U}_{4} \mathrm{O}_{9}$. This conclusion is consistent with that obtained by XANES and EXAFS if the XPS-determined U(VI) component is restricted to the near-surface and was not measurable by XAS, whereas the $\mathrm{UO}_{2}$ component (see Section 3.4.1.) is restricted to the particle core and was not measurable by XPS. Note that because the L-edge position for $\mathrm{U}(\mathrm{V})$ can be similar to that for $\mathrm{U}(\mathrm{VI})$, the XANES results cannot exclude U(V).

Another salient result that supports the presence of an outermost oxidized layer that was not detected by XAS is that the experiments reached saturation with respect to metaschoepite, which is consistent with the XPS-deter- mined $\mathrm{U} 4 f$ binding energies of the dominant $\mathrm{U}(\mathrm{VI})$ component. Because metaschoepite, or any likely uranyl(VI) precipitate under the experimental conditions, should have the short uranyl axial bond, it is clear that EXAFS and XANES did not detect this outermost oxidized layer. Thus, as discussed later, the cumulative results are compatible with zoned particles consisting of a metaschoepite-like outer layer, a $\mathrm{U}_{4} \mathrm{O}_{9}$ intermediate layer containing $50 \% \mathrm{U}(\mathrm{V})$ and $50 \% \mathrm{U}(\mathrm{IV})$, and a $\mathrm{UO}_{2.00}$ core.

The XPS analysis detected a higher proportion of $\mathrm{U}(\mathrm{VI})$ on the surface of $\mathrm{UO}_{2}$ dissolving in the SBR compared to the material dissolving in the CFR. This result likely reflects the longer reaction time of the SBR experiment and the continuous flushing of the reactor for greater removal of $\mathrm{U}(\mathrm{VI})$ by carbonate in the CFR experiment. In contrast to the original untreated syn- $\mathrm{UO}_{2}$ material, the near-surface of all the treated and partially dissolved materials had significant proportions of $\mathrm{U}(\mathrm{VI})$ and $\mathrm{U}(\mathrm{V})$, which further illustrates the impact of surface oxidation under both anoxic and oxic conditions and the unexpectedly high stability of a near-surface U(V) component (see Section 4.1., below). 
Table 2

Percentage of $\mathrm{U}(+\mathrm{IV}), \mathrm{U}(+\mathrm{V})$, and $\mathrm{U}(+\mathrm{VI})$ as determined by $\mathrm{X}$-ray photoelectron spectroscopy $(\mathrm{XPS})$ on synthetic and biogenic $\mathrm{UO} \mathrm{O}_{2}$ before and after continuous-flow dissolution treatments.

\begin{tabular}{|c|c|c|c|c|}
\hline Sample & Treatment condition & $\mathrm{U}(+\mathrm{IV})$ & $\mathrm{U}(+\mathrm{V})$ & $\mathrm{U}(+\mathrm{VI})$ \\
\hline Syn- $\mathrm{UO}_{2}$ & Original dry solid & 100 & 0 & 0 \\
\hline Syn- $\mathrm{UO}_{2}$ & Anoxic diss, $\mathrm{pH} 7.30$ & $75(75)$ & $18(18)$ & $7(7)$ \\
\hline Syn- $\mathrm{UO}_{2}$ & Anoxic diss, pH 7.31 & $71(69)$ & $20(21)$ & $9(10)$ \\
\hline Syn- $\mathrm{UO}_{2}$ & Anoxic diss, $\mathrm{pH} 2.1$ & $76(76)$ & $18(18)$ & $6(6)$ \\
\hline Syn- $-\mathrm{UO}_{2}{ }^{\mathrm{d}}$ & Anoxic diss, $\mathrm{pH} 8.5,1 \mathrm{mM}$ DIC & a 79 & ${ }^{\mathrm{a}} 14$ & $a_{7}$ \\
\hline Syn- $\mathrm{UO}_{2}$ & Oxic diss, $\mathrm{pH} 7.6,1 \% \mathrm{P}_{\mathrm{O} 2}$ & $56(55)$ & $28(28)$ & $16(17)$ \\
\hline Syn- $\mathrm{UO}_{2}{ }^{\mathrm{d}}$ & Oxic diss, $\mathrm{pH} 8.3,1 \mathrm{mM}$ DIC, Air, SBR & $17(16)$ & $17(16)$ & $66(68)$ \\
\hline Bio6-UO $\mathrm{UO}_{2}$ & Original slurry, dried & $88(87)$ & 0 & $12(13)$ \\
\hline Bio6- $\mathrm{UO}_{2}$ & $1 \mathrm{M} \mathrm{NaOH}$ & $49(48)$ & $45(49)$ & $6^{\mathrm{b}}(3)$ \\
\hline Bio6- $\mathrm{UO}_{2}$ & $1 \mathrm{M} \mathrm{NaOH}$, anoxic diss, $\mathrm{pH} 7.40$ & $39(37)$ & $40(41)$ & $21(22)$ \\
\hline $\mathrm{Bio} 8-\mathrm{UO}_{2}$ & Original slurry, dried & $84^{\mathrm{c}}(83)$ & $8^{c}(9)$ & $8^{c}(8)$ \\
\hline $\mathrm{Bio} 8-\mathrm{UO}_{2}$ & $1 \mathrm{M} \mathrm{NaOH}$ & $52(50)$ & $36(36)$ & $12(14)$ \\
\hline $\mathrm{Bio} 8-\mathrm{UO}_{2}$ & $1 \mathrm{M} \mathrm{NaOH}$, anoxic diss, $\mathrm{pH} 2.1$ & $69(67)$ & $22(23)$ & $9(10)$ \\
\hline
\end{tabular}

Values rounded off to integers. Numbers in parentheses are extrapolated time 0 values, unless otherwise noted.

a Sequential analyses not performed.

b Unexplained unusual behavior.

c Average value, no discernable reduction trend.

d Material of different production batch.

\section{DISCUSSION}

\subsection{Mechanistic model for aqueous $\mathrm{UO}_{2+x}$ dissolution}

Among the potential physicochemical parameters controlling uraninite dissolution in groundwater (e.g., $\mathrm{H}^{+}$, oxidants, ligands, temperature), oxygen and carbonate are the most important variables under natural $\mathrm{pH}$ conditions. Extensive information is available on the corrosion of spent fuel and synthetic $\mathrm{UO}_{2(\mathrm{~s})}$ as a function of oxygen and carbonate concentrations (for review see Shoesmith (2000)). According to the literature, the dissolution process can be described by a three-step mechanism, (a) coordination of oxygen to the U(IV) surface followed by direct electron transfer (redox reaction), (b) surface coordination of carbonate to $\mathrm{U}(\mathrm{VI})$, and (c) detachment of a $\mathrm{U}(\mathrm{VI})-\mathrm{CO}_{3(\mathrm{aq})}$ species (Bruno et al., 1995; De Pablo et al., 1999). At low $P_{\mathrm{O} 2}$, uraninite dissolution is controlled by sorption of oxygen to the surface and thus is expected to be independent of the carbonate concentration. At high $P_{\mathrm{O} 2}$, carbonate coordination with $\mathrm{U}(\mathrm{VI})$ and complex detachment are expected to be rate-limiting until the [DIC] exceeds the concentration of surface bound U(VI). Both effects are reported in the literature and were consistently predicted using the general reaction model by De Pablo et al. (1999).

The present study indicates higher complexity of the $\mathrm{UO}_{2+x}$ dissolution processes. Dependent on the chemical conditions, the oxidative dissolution of $\mathrm{UO}_{2}$ particles can involve an intermediate $\mathrm{U}(\mathrm{V})$ species and lead to the formation of surface layers with distinct hyperstoichiometry including $\mathrm{UO}_{2.25}\left(\mathrm{U}_{4} \mathrm{O}_{9}\right)$. In synthesizing our experimental and spectroscopic results, we propose a slightly modified concept of the aqueous $\mathrm{UO}_{2(\mathrm{~s})}$ dissolution, the key steps of which are illustrated in Fig. 6 for reducing (Fig. 6A-C) and oxidizing conditions (Fig. 6D-F) regardless of the origin of the material (biogenic or chemogenic $\mathrm{UO}_{2+x}$ ).

\subsubsection{Reducing conditions (no DIC)}

The original chemogenic $\mathrm{UO}_{2.0}$ exhibited $\mathrm{U}(\mathrm{IV})$ both in the bulk and on the particle surface, as shown by XAS and XPS analyses. Furthermore, KPA analysis excluded dissolved U(VI) in the effluent based on a detection limit of $4.2 \times 10^{-10} \mathrm{M}$. Although the oxidation state remains uncertain for a fraction of $10-15 \%$ of the dissolved uranium, the ICP-MS results suggest a predominance of U(IV $)_{\text {aq }}$. Hence, the main dissolution reaction for materials in contact with anoxic water at near-neutral $\mathrm{pH}$ is $\mathrm{U}(\mathrm{IV})$ hydrolysis (Eq. (7)), a conclusion that is consistent with the proton-promoted mechanism driving $\mathrm{UO}_{2+x}$ dissolution under acidic conditions (Ulrich et al., 2008).

Despite the lack of detectable U(VI) in solution, XPS recorded $7-10 \% \mathrm{U}(\mathrm{VI})$ and $\sim 20 \% \mathrm{U}(\mathrm{V})$ near the syn- $\mathrm{UO}_{2}$ surface after being suspended in anoxic, DIC-free water (Fig. 5b). The occurrence of $\mathrm{U}(\mathrm{V})$ and trace amounts of $\mathrm{U}(\mathrm{VI})$ on the chemogenic $\mathrm{UO}_{2}$ suggests partial surface oxidation even under the reducing conditions in the experiments. The presence of $\mathrm{U}(\mathrm{V})$ on $\mathrm{UO}_{2}$ is of particular interest because, to the best of our knowledge, it has not been reported in previous laboratory-based corrosion studies of synthetic $\mathrm{UO}_{2(\mathrm{~s})}$. However, a series of papers on the anodic dissolution of SIMFUEL (uranium dioxide doped with trivalent rare earth elements to increase the electronic conductivity), where the surface state of the $\mathrm{UO}_{2}$ electrode was monitored with XPS, have reported U(V) for a wide range of solution compositions and applied potentials (Santos et al., 2004, 2006). This raises the possibility that desorption of surface bound $\mathrm{U}(\mathrm{V})$ could be contributing to the $\mathrm{U}$ concentrations determined by ICP-MS; any $\mathrm{U}(\mathrm{V})_{\text {aq }}$ present at such low concentrations might be stable with respect to disproportionation. It further raises the possibility that $\mathrm{UO}_{2(\mathrm{~s})}$ solubility in water might be affected by $\mathrm{U}(\mathrm{V})_{\mathrm{aq}}$ resulting from surface oxidation of $\mathrm{U}(\mathrm{IV})$ under anoxic conditions. 


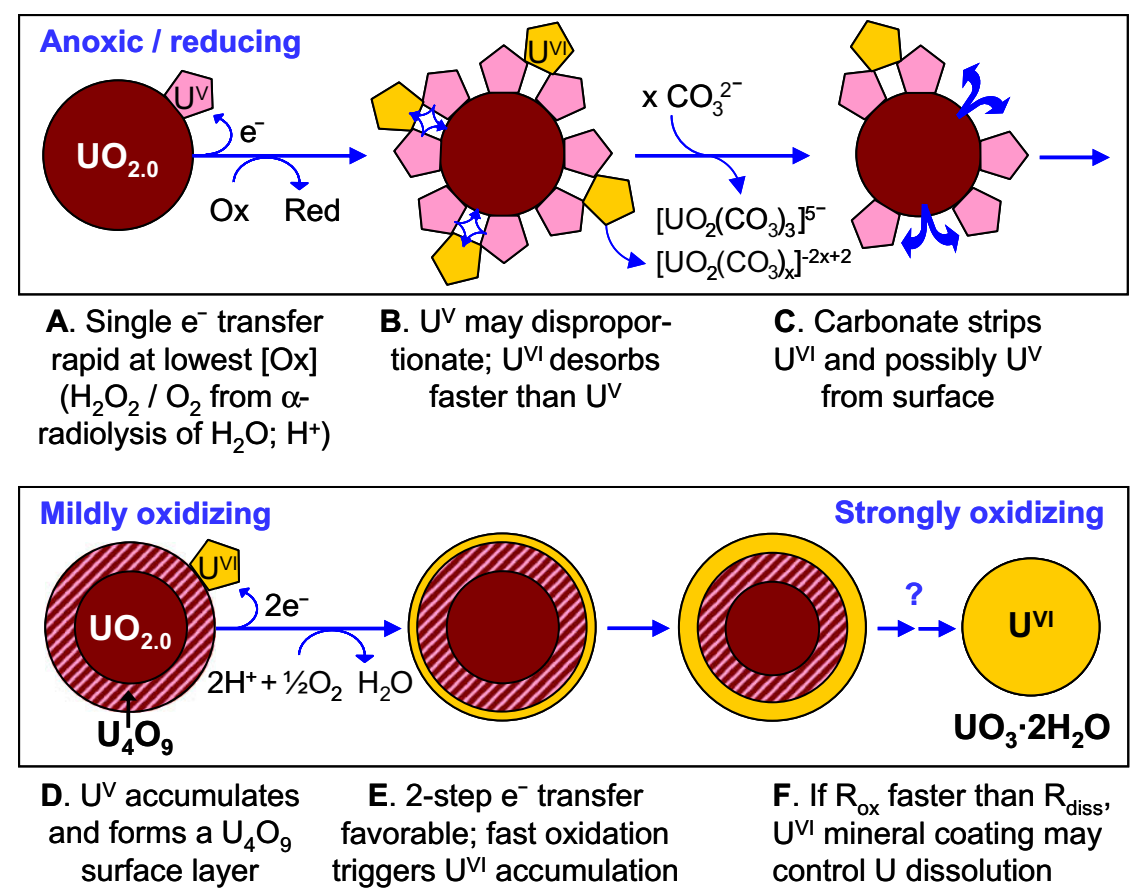

Fig. 6. Conceptual model of mechanisms of $\mathrm{UO}_{2}$ dissolution. Balls and pentagons represent particles and ions attached to the surface, respectively. Details are explained in the text.

\subsubsection{Origin of oxidants under reducing conditions}

Water and its dissociation and radiolysis products can act as oxidants of $\mathrm{UO}_{2}$. For natural uranium, water radiolysis is mainly caused by alpha radiation from ${ }^{238} \mathrm{U}$ and ${ }^{234} \mathrm{U}$ (each $\sim 49 \%$ of activity). While the most important oxidants are $\mathrm{H}_{2} \mathrm{O}_{2}$ and $\mathrm{O}_{2}, \mathrm{H}^{+}, \mathrm{HO}_{2}{ }^{-}$and free radicals can also be relevant (Clarens et al., 2005; Eriksen et al., 1995). A comprehensive list of reaction pathways and products is given elsewhere (Christensen, 1998; Christensen et al., 1994).

The yield of $\alpha$-radiolytic $\mathrm{H}_{2} \mathrm{O}_{2}$ generated in a CFR loaded with nanoparticulate ${ }^{238} \mathrm{UO}_{2}$ can be estimated from the specific activity of the isotope ${ }^{238} \mathrm{U}(12,445 \mathrm{~Bq} / \mathrm{g})$. Assuming that there is no attenuation of $\alpha$-radiation within submicron particles, the radiation dose will be independent of the surface area. Given the alpha activity of $1 \mathrm{~g}$ of ${ }^{238} \mathrm{UO}_{2}\left(6.58 \times 10^{5} \mathrm{dpm}\right.$, disintegrations per minute), the alpha particle energy of $5.5 \times 10^{6} \mathrm{eV}$ and a product yield of $0.00985 \mathrm{H}_{2} \mathrm{O}_{2}$ molecules per $\mathrm{eV}$ in neutral water (Eriksen et al., 1995), and assuming a $40 \mu \mathrm{m}$ radius for the energy range of an emitted alpha particle in water (Kubatko et al., 2003) as well as conservative behavior for $\mathrm{H}_{2} \mathrm{O}_{2}$ (neither decay nor consumption), the $\mathrm{H}_{2} \mathrm{O}_{2}$ concentration in the CFR at steady-state can be calculated. Using a $\mathrm{UO}_{2(\mathrm{~s})}$ concentration of $1 \mathrm{~g} / \mathrm{L}$ and integrating the $\alpha$-activity over a residence time of $6 \mathrm{~min}$, the $\mathrm{H}_{2} \mathrm{O}_{2}$ concentration would reach $3.55 \times 10^{-13} \mathrm{M}$. Because this concentration is too low to account for the oxidation of a surface monolayer on uraninite under the experimental conditions, other oxidants are likely involved, for instance $\mathrm{H}_{2} \mathrm{O}$. In addition, $\mathrm{O}_{2}$ can result from the decomposition of peroxide, the reduction of which was shown to be catalyzed by the formation of a thin surface layer of a mixed $U(I V) / U(V)$ oxide
$\left(\mathrm{UO}_{2+x}\right)$ until surface adsorbed $\mathrm{U}(\mathrm{VI})$ species begin to form (Goldik et al., 2004).

\subsubsection{Surface oxidation under reducing conditions}

Even if the concentrations of potential oxidants such as $\mathrm{H}_{2} \mathrm{O}_{2}, \mathrm{O}_{2}$ or $\mathrm{H}^{+}$are extremely low, each molecule coming close to the $\mathrm{UO}_{2}$ surface may transfer electrons to a U(IV) site. Thus, over time, the surface can become more and more oxidized. Interestingly, the XPS data consistently showed $\mathrm{U}(\mathrm{V})$ at a higher percentage than $\mathrm{U}(\mathrm{VI})$ on the anoxic syn- $\mathrm{UO}_{2}$ surface. This is consistent with an oxidation mechanism that involves a relatively fast single electron transfer reaction to form $\mathrm{U}(\mathrm{V})$ (Eq. (10), Fig. 6A) followed by a slower second electron transfer to form U(VI) (Eq. (11), Fig. 6D).

$$
\begin{aligned}
& \mathrm{UO}_{2}+\mathrm{H}_{2} \mathrm{O} \rightarrow\left(\mathrm{U}^{\mathrm{V}} \mathrm{O}_{2} \mathrm{OH}\right)_{\mathrm{ads}}+\mathrm{H}^{+}+\mathrm{e}^{-}{ }_{(\mathrm{aq})} \\
& {\left[\left(\mathrm{U}^{\mathrm{V}} \mathrm{O}_{2} \mathrm{OH}\right)\right]_{\mathrm{ads}}+\mathrm{H}_{2} \mathrm{O} \rightarrow\left[\mathrm{U}^{\mathrm{VI}} \mathrm{O}_{2}(\mathrm{OH})_{2}\right]_{\mathrm{ads}}+\mathrm{H}^{+}+\mathrm{e}^{-}{ }_{(\mathrm{aq})}}
\end{aligned}
$$

A similar oxidation mechanism was suggested for the anodic dissolution of SIMFUEL (Santos et al., 2004, 2006) based on the apparent coincident prominence of $\mathrm{U}(\mathrm{V})$ and $\mathrm{OH}^{-}$in their XPS spectra, prompting the authors to hypothesize that an intermediate $\mathrm{U}(\mathrm{V})$ species was stabilized on the $\mathrm{UO}_{2}$ surface in a hydrolyzed form (Eq. (10)).

Disproportionation of $\mathrm{U}(\mathrm{V})$ is another potential reaction pathway (Eq. (12)) that can limit the accumulation of $\mathrm{U}(\mathrm{V})$ and explain the occurrence of $\mathrm{U}(\mathrm{VI})$ on the $\mathrm{UO}_{2+x}$ surface under reducing conditions (Fig. 6B).

$$
2\left(\mathrm{U}^{\mathrm{V}} \mathrm{O}_{2} \mathrm{OH}\right)_{\mathrm{ads}} \rightarrow \mathrm{U}^{\mathrm{IV}} \mathrm{O}_{2}+\left[\mathrm{U}^{\mathrm{VI}} \mathrm{O}_{2}(\mathrm{OH})_{2}\right]_{\mathrm{ads}}
$$


Depending on the concentration of $\mathrm{U}(\mathrm{V})_{\mathrm{aq}}$ in solution, rapid disproportionation of $\mathrm{U}(\mathrm{V})$ at the $\mathrm{pH}$ of the experiments would be expected. However, there is no firm evidence that sorbed $\mathrm{U}(\mathrm{V})$ is unstable with respect to disproportionation. Although this stability may depend on the substrate to which $\mathrm{U}(\mathrm{V})$ is sorbed, evidence from mica surfaces suggests that sorbed $U(V)$ does not readily disproportionate (Ilton et al., 2005). Consequently, the most likely reaction pathway is sequential oxidation of $\mathrm{U}(\mathrm{IV})$ to $\mathrm{U}(\mathrm{V})$ to $\mathrm{U}(\mathrm{VI})$.

\subsubsection{Effects of carbonate under reducing conditions}

The continuous partial oxidation of the $\mathrm{UO}_{2+x}$ surface under reducing conditions is also illustrated by the way carbonate affects uranium release. According to thermodynamic data (Guillaumont et al., 2003) carbonate is a weak complexant for U(IV) and thus should not enhance $\mathrm{UO}_{2+x}$ dissolution under strictly reducing conditions and at the carbonate and $\mathrm{pH}$ levels of the experiments. However, our results showed that carbonate accelerated $\mathrm{UO}_{2}$ dissolution. Carbonate is known as a strong complexant for actinyl ions. Its presence in a $\mathrm{UO}_{2(\mathrm{~s})}-\mathrm{H}_{2} \mathrm{O}$ system can accelerate the detachment of $\mathrm{U}(\mathrm{VI})$ from the $\mathrm{UO}_{2+x}$ surface once U(VI) has been formed, thus promoting $\mathrm{U}(\mathrm{IV})$ oxidation. Although $\mathrm{U}(\mathrm{V})$-carbonate species are less stable than U(VI)-carbonate complexes (Guillaumont et al., 2003), they may act in a similar way and promote the oxidation of U(IV) to $\mathrm{U}(\mathrm{V})$ by facilitating the detachment of $\mathrm{U}(\mathrm{V})$ from the $\mathrm{UO}_{2+x}$ surface (Fig. 6C). Eq. (13) gives an example of such a surface reaction based on the aqueous $\mathrm{U}(\mathrm{V})$-carbonate species $\left[\mathrm{UO}_{2}\left(\mathrm{CO}_{3}\right)_{3}\right]^{5-}$ that has been resolved by means of XAS (Docrat et al., 1999).

$\left[\mathrm{U}^{\mathrm{V}} \mathrm{O}_{2}(\mathrm{OH})\right]_{\mathrm{ads}}+3 \mathrm{CO}_{3}{ }^{2-} \rightarrow\left[\mathrm{UO}_{2}\left(\mathrm{CO}_{3}\right)_{3}\right]^{5-}+\mathrm{OH}^{-}$

If in an anoxic flow-through system the carbonate-promoted rate of $\mathrm{U}(\mathrm{V})$ and $\mathrm{U}(\mathrm{VI})$ detachment from the $\mathrm{UO}_{2+x}$ surface is faster than the rate of U(IV) oxidation, then the introduction of carbonate should produce an initial $[U]_{\text {diss }}$ peak as the accumulated $\mathrm{U}(\mathrm{V})$ and $\mathrm{U}(\mathrm{VI})$ is removed. The peak would be followed by a continuous decline of $[U]_{\text {diss }}$ to a new steady-state level. This trend was observed for the syn- $\mathrm{UO}_{2}$ when treated with anoxic $1 \mathrm{mM}$ DIC solution (Fig. 2c). In the anoxic flow-through experiment in which carbonate was intermittently supplied, the effluent $[U]_{\text {diss }}$ increased while carbonate was present, but rapidly returned to the initial steady-state concentration after the initial conditions were re-established (Fig. 3A). These results illustrate that carbonate did not change the intrinsic oxidation kinetics of $\mathrm{UO}_{2}$ (because it is not an oxidant), but rather it affected the detachment rate of $\mathrm{U}(\mathrm{IV})$ oxidation products from the $\mathrm{UO}_{2+x}$ surface.

\subsubsection{Oxidizing conditions}

The dissolution experiments and concomitant spectroscopic investigations showed a clear response to the increase in oxidant concentration. Even at a DO concentration as low as $0.4-0.6 \mathrm{mg} / \mathrm{L}$ (maintained by a $P_{\mathrm{O} 2}$ of 0.01 bar in the headspace of the feed solution vessel), the fraction of $\mathrm{U}(\mathrm{V})$ and $\mathrm{U}(\mathrm{VI})$ near the $\mathrm{UO}_{2}$ surface increased to $28 \%$ and $17 \%$ of total U (Table 2). Similarly, the KPA detected dissolved U(VI) in the effluent, but this fraction represented only $5-10 \%$ of the effluent $[U]_{\text {diss. }}$ Because the concentration of the remaining $90-95 \%$ of $[U]_{\text {diss }}$ far exceeded the expected equilibrium concentration of $\mathrm{U}(\mathrm{IV})_{\mathrm{aq}}$, the KPA analyses suggest the presence of another uranium component in solution, likely $\mathrm{U}(\mathrm{V})_{\mathrm{aq}}$. Even stronger changes occurred when the $[\mathrm{DO}]$ was raised to $\sim 9 \mathrm{mg} / \mathrm{L}$ in equilibrium with air. The proportion of near-surface $\mathrm{U}(\mathrm{VI})$ increased to $44 \%$ at the expense of U(IV) (Table 2 ), and U(VI) became the predominant fraction of the effluent $[U]_{\text {diss }}$ at about $80 \%$. The dissolution rates of syn- $\mathrm{UO}_{2}$ increased by a factor of $\sim 10$ (from $6 \times 10^{-10}$ to $\left.5 \times 10^{-9} \mathrm{~mol} \mathrm{~m}^{-2} \mathrm{~s}^{-1}\right)$ when switching from $1 \%$ to $21 \%$ $P_{\mathrm{O} 2}$ (Table 1). Because the DIC concentration was kept constant, the increase in dissolution rate reflects the expected strong dependency of the oxidation rate on the oxidant concentration.

When the supply of DO was stopped in the intermittent DO dissolution study (Fig. 3B), the effluent $[U]_{\text {diss }}$ did not decline. Rather, the steady-state concentration remained unchanged for about 20 residence times, although the feed solution in this intermittent experiment never contained any carbonate. This result suggests that the detachment of $\mathrm{U}(\mathrm{VI})$ and possibly $\mathrm{U}(\mathrm{V})$ was rate-limiting while DO was supplied in the absence of carbonate, leading to an accumulation of oxidized $\mathrm{U}$ near the $\mathrm{UO}_{2+x}$ surface (Fig. $6 \mathrm{~F}$ ). This observation is consistent with literature describing a decreasing hyperstoichiometry of the syn- $\mathrm{UO}_{2}$ surface with increasing carbonate concentration under oxidizing conditions. While higher stoichiometric ratios of $\mathrm{O}: \mathrm{U}$ were reported in the absence of bicarbonate $(x=0.35-0.38$, Bruno et al. (1995), de Pablo et al. (1996)), treatment with 0.1 and $1.0 \mathrm{mM}$ DIC solution yielded $x=0.20$ (Gimenez et al., 2005), and an even lower value of $x=0.05$ was found after the treatment of syn- $\mathrm{UO}_{2}$ with a $10 \mathrm{mM}$ DIC solution (De Pablo et al., 1996; Gimenez et al., 2005). Gimenez et al. (2005) concluded in their study that the non-stoichiometry was not due to deposition of a secondary solid phase. Torrero et al. (1997) determined an average solid surface stoichiometry of $\mathrm{UO}_{2.25}$ at $\mathrm{pH} 8.2$ as opposed to $\mathrm{UO}_{2.0}$ at $\mathrm{pH} 5$ and explained this difference by a diminishing rate of proton-promoted dissolution with increasing $\mathrm{pH}$, enabling the incorporation of $\mathrm{O}^{2-}$ species into the $\mathrm{UO}_{2}$ lattice. Thus, in the absence of more soluble aqueous U-carbonate species at neutral and alkaline conditions, the oxidative dissolution of $\mathrm{UO}_{2+x}$ will be controlled by the detachment of $\mathrm{U}(\mathrm{VI})$ and $\mathrm{U}(\mathrm{V})$ from the $\mathrm{UO}_{2+x}$ surface.

The highest $\mathrm{U}(\mathrm{VI})$ fraction on a syn- $\mathrm{UO}_{2}$ surface $(68 \%$ of total $\mathrm{U}$ ) was determined by XPS in a SBR-based dissolution experiment in which syn- $\mathrm{UO}_{2}$ was exposed to a $1 \mathrm{mM}$ DIC solution open to air atmosphere. For this material, as outlined previously, the combined results of XANES, EXAFS and XPS suggest layered zones. A $\mathrm{U}(\mathrm{VI})$-rich outer layer in which the binding energy is consistent with uranyl(VI) was identified by surface-sensitive XPS but not by XANES or EXAFS, a $\mathrm{U}_{4} \mathrm{O}_{9}$ middle layer containing $\mathrm{U}(\mathrm{IV})$ and $\mathrm{U}(\mathrm{V})$ for which both XPS and XANES are sensitive, and a core composed of $\mathrm{UO}_{2.00}$ that is accessible to XANES but not to XPS (Fig. 6F). The lack of the transdioxo bonding structure as evidenced by EX- 
AFS suggests that $\mathrm{U}(\mathrm{V})$ must not be present as the $\mathrm{UO}_{2}{ }^{+}$ cation and therefore we speculate that it can occupy $\mathrm{UO}_{2}$ lattice sites as defects. Previous investigations have concluded that $\mathrm{U}_{4} \mathrm{O}_{9}$ contains both $\mathrm{U}(\mathrm{IV})$ and $\mathrm{U}(\mathrm{V})$ (Allen and Holmes, 1993). The clear evidence for $\mathrm{U}^{6+}$ from XPS on the other hand strongly supports the concept of a surface coating distinct from $\mathrm{U}_{4} \mathrm{O}_{9}$, consistent with a mineral phase like metaschoepite. The possibility that $\mathrm{U}(\mathrm{V})$ is incorporated at lattice sites, most likely within the $\mathrm{U}_{4} \mathrm{O}_{9}$ middle layer, might explain the surprisingly high stability of $U(V)$ near the particle surface.

In conclusion, it is sufficient that all the XPS spectra are best fit with three components that are derived from wellcharacterized $\mathrm{U}(\mathrm{IV}), \mathrm{U}(\mathrm{V})$, and $\mathrm{U}(\mathrm{VI})$ standards and that these components maintain their separate and independent identities over a wide range of average oxidation states. Further investigation is needed to understand the formation and evolution of the proposed multi-layer oxidation structure.

\subsection{Carbonate-promoted $\mathrm{UO}_{2+x}$ oxidation}

Whereas several uraninite dissolution studies have been conducted under atmospheric $P_{\mathrm{O} 2}$, the present work investigated the effect of carbonate on the stability of bio- and chemogenic $\mathrm{UO}_{2}$ at a moderate $P_{\mathrm{O} 2}$ level of $1 \mathrm{vol} \%$ to simulate mildly oxidizing groundwater (Fig. 7; note that rates are compared as a function of $\left[\mathrm{CO}_{3}{ }^{2-}\right]$ and not [DIC]). Although the dissolution rates of bio- $\mathrm{UO}_{2}$ were slightly higher than those of syn- $\mathrm{UO}_{2}$ on a mass basis (Fig. 7a), they were lower when normalized to surface area except for the highest carbonate concentration tested (Fig. 7b). For both materials the dissolution rates increased with a similar slope up to roughly $5 \times 10^{-6} \mathrm{M} \mathrm{CO}_{3}{ }^{2-}$. Beyond this concentration, the dissolution rates of bio- $\mathrm{UO}_{2} \mathrm{kept}$ increasing at a lower rate, while those of syn- $\mathrm{UO}_{2}$ decreased slightly. Irrespective of whether or not this decrease is a real trend or an experimental artifact due to the sequential treatment of the material, the site density of surface-associated, carbonate-accessible U(VI) can be estimated by assuming that all sites were saturated with $\mathrm{CO}_{3}{ }^{2-}$ when the dissolution rate reached its maximum. By multiplying $\left[\mathrm{CO}_{3}{ }^{2-}\right]$ by Avogadro's number and dividing by the product of $S S A\left(6 \mathrm{~m}^{2} / \mathrm{g}\right)$ and solids concentration $(1 \mathrm{~g} / \mathrm{L})$, a carbonate-accessible site density of $0.5 \mathrm{~nm}^{-2}$ is calculated for the syn- $\mathrm{UO}_{2}$. This number is very close to the $>\mathrm{U}(\mathrm{VI})$ site density of $0.6 \mathrm{~nm}^{-2}$ used in the study of De Pablo et al. (1999). For the bio- $\mathrm{UO}_{2}$ particles, the unknown degree of aggregation and thus uncertainty in their effective surface area made it impossible to calculate a meaningful $>\mathrm{U}(\mathrm{VI})$ site density for the purpose of comparison.

The log-linear relationship between dissolution rate and $\left[\mathrm{CO}_{3}{ }^{2-}\right]$ (Fig. 7 b) is consistent with the literature (De Pablo et al., 1999). Above a threshold $\mathrm{CO}_{3}{ }^{2-}$ concentration the rate becomes independent of $\left[\mathrm{CO}_{3}{ }^{2-}\right]$. This pattern is consistent with a surface-controlled dissolution mechanism mediated by the binding of carbonate to initially oxidized $>\mathrm{U}(\mathrm{VI})$ surface sites. The dissolution of bio- $\mathrm{UO}_{2}$ is comparable to that of syn- $\mathrm{UO}_{2}$ in that it strongly depends on the carbonate concentration even in oxygen-limited $(0.4$ $0.5 \mathrm{mg} \mathrm{DO} / \mathrm{L}$ ) neutral water.

Under nominally reducing conditions, carbonate is not expected to accelerate the $\mathrm{UO}_{2}$ dissolution because carbonate is a strong complexing agent for $\mathrm{UO}_{2}{ }^{2+}$ but not for $\mathrm{U}^{4+}$ under the given experimental conditions (Shoesmith, 2000). However, as discussed earlier, water radiolysis products can partially oxidize the $\mathrm{UO}_{2+x}$ surface and lead to the accumulation of corrosion product deposits such as $\mathrm{UO}_{2.25}$ or $\mathrm{UO}_{2.33}$ (Shoesmith, 2000). Although such deposits may reduce the rate of $\mathrm{UO}_{2+x}$ dissolution, the self-stabilization of the surface against corrosion would be counteracted by increasing carbonate concentration. The accelerating effect on $\mathrm{UO}_{2+x}$ dissolution was clearly demonstrated by the increase in effluent $[U]_{\text {diss }}$ upon the supply of DIC under reducing conditions (Fig. 1a-c). Another likely indicator of rapid dissolution of oxidized deposits on the $\mathrm{UO}_{2+x}$ surface is the transient peaks in the effluent $[U]_{\text {diss }}$ observed after switching from a lower to a higher DIC concentration in the feed solution (Fig. 2). This feature suggests continuous accumulation of $\mathrm{U}(\mathrm{V})$ and/or $\mathrm{U}(\mathrm{VI})$ on the $\mathrm{UO}_{2+x}$
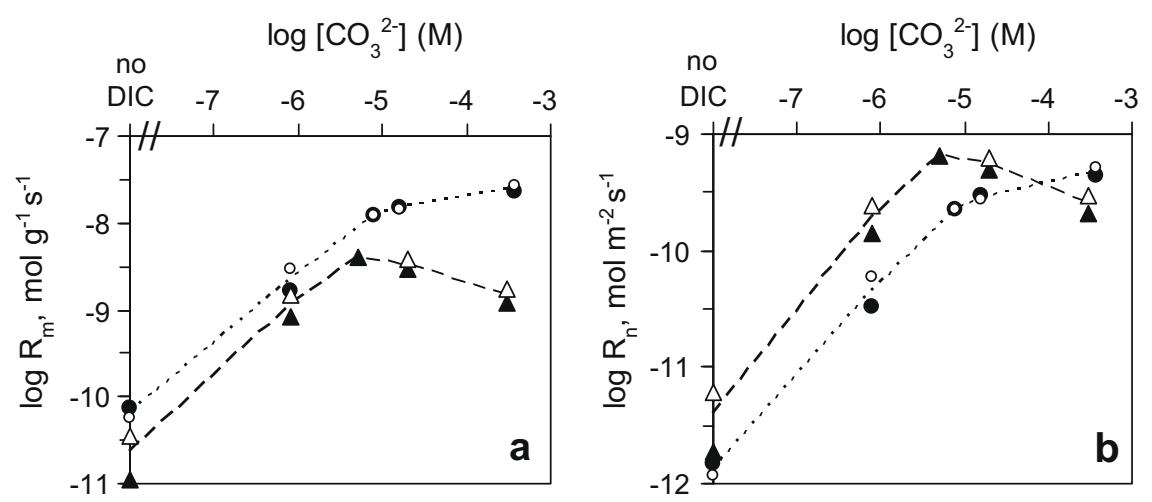

Fig. 7. Rates of $\mathrm{UO}_{2}$ dissolution by duplicates of bio6- $\mathrm{UO}_{2}(\bullet, O)$ and syn- $\mathrm{UO}_{2}(\boldsymbol{\Lambda}, \Delta)$ solids determined under moderately oxidizing conditions $\left(1 \mathrm{vol} \% P_{\mathrm{O} 2}\right)$ as a function of $\mathrm{CO}_{3}{ }^{2-}$ concentration. (a) Rates $R_{m}$ are given per unit mass and time. (b) The surface area-normalized dissolution rates seem to become independent of carbonate at $\left[\mathrm{CO}_{3}{ }^{2-}\right]>10^{-5} \mathrm{M}$, suggesting saturation of the carbonate-accessible $\mathrm{U}(\mathrm{VI})$ surface sites. 
surface even during steady-state flow conditions and a fast desorption reaction when providing higher carbonate concentrations.

The average dissolution rates of syn- $\mathrm{UO}_{2}$ from this study can be compared with previously published data. The rate obtained under a $1 \mathrm{vol}^{\%} \quad P_{\mathrm{O} 2}$ atmosphere at $0.1 \mathrm{mM}$ DIC and pH $8.2\left(2.0 \times 10^{-10} \mathrm{~mol} \mathrm{~m}^{-2} \mathrm{~s}^{-1}\right)$ was similar to numbers reported for higher DIC concentrations and in the presence of air (Table 1). For example, Pierce et al. (2005) measured a rate of $1.0 \times 10^{-10} \mathrm{~mol} \mathrm{~m}^{-2} \mathrm{~s}^{-1}$ for the dissolution of crystalline $\mathrm{UO}_{2}$ at $10^{-3} \mathrm{M}$ DIC and $\mathrm{pH}$ 8.0. A rate of $1.6 \times 10^{-10} \mathrm{~mol} \mathrm{~m}^{-2} \mathrm{~s}^{-1}$ was obtained when dissolving syn- $\mathrm{UO}_{2}$ at $10^{-2} \mathrm{M}$ DIC and $\mathrm{pH} 8.5$ (Bruno et al., 1995; De Pablo et al., 1996). In contrast, the dissolution rate of syn- $\mathrm{UO}_{2}$ determined in the present study under atmospheric conditions, $1 \mathrm{mM}$ DIC and $\mathrm{pH} 8.0$ $\left(4.8 \times 10^{-9} \mathrm{~mol} \mathrm{~m}^{-2} \mathrm{~s}^{-1}\right)$ was 48-times higher than the rate published for similar conditions (Pierce et al., 2005). This discrepancy can be due to the higher flow rate and the sequential treatment of the $\mathrm{UO}_{2+x}$ material used in our study.

In natural groundwater, divalent earth alkali cations such as $\mathrm{Ca}^{2+}$ and $\mathrm{Mg}^{2+}$ are common constituents that can form very stable aqueous complexes with uranyl carbonate (Dong and Brooks, 2006). Hence, such species may accelerate $\mathrm{UO}_{2}$ dissolution in a similar manner to carbonate alone, by accelerating the detachment of surfaceassociated oxidized uranium species. Divalent cations may also interact with $\mathrm{U}(\mathrm{V})$ carbonato complexes, but it is unknown whether such species would favor enhanced dissolution or potentially stabilize the $\mathrm{U}_{4} \mathrm{O}_{9}$ surface layer.

\subsection{Comparison of bio- $\mathrm{UO}_{2}$ and $\mathrm{syn}-\mathrm{UO}_{2}$ dissolution}

The cleaned biogenic and the chemogenic uraninite solids exhibited similar dissolution trends and comparable rates under the experimental conditions, with one exception. Although the steady-state concentrations of dissolved uranium were generally higher for the bio- $\mathrm{UO}_{2}$ compared to the syn- $\mathrm{UO}_{2}$ (Figs. 1 and 2), the dissolution rates generally agreed within a factor 2-4 when normalized to the BET surface area (Table 1). Given the complexity of the dissolution experiments and the number of variables that add uncertainty to the systems (e.g., mass and homogeneity of the initial solids, analytical uncertainties, variation among replicates), differences in rates within a factor of 4 are not likely to be significant. Based on this result, within the margin of experimental uncertainty, the tested biogenic and synthetic $\mathrm{UO}_{2}$ materials exhibited similar reactivity with respect to oxidative and carbonate-promoted dissolution, where the detachment of $\mathrm{U}(\mathrm{VI})$ and probably $\mathrm{U}(\mathrm{V})$ is the dissolution rate-limiting step. This similarity in reactivity of the two size fractions $(\sim 3 \mathrm{~nm}$ and $100-200 \mathrm{~nm}$ particles) implies that the principal surface reactions, at least the rates of oxidation and dissolution, are comparable. This in turn suggests similar types and densities of reactive surface sites und thus surface free energy. A similar conclusion was obtained with regard to $\mathrm{Zn}(\mathrm{II})$ sorption on biogenic, nanoparticulate $\mathrm{UO}_{2}$ and bulk uraninite (Singer et al., 2009).
The exception to the trend of similar reactivity for the biogenic and chemogenic uraninites in the present study is the observation made under reducing conditions in the presence of carbonate, where the dissolution rate of bio6$\mathrm{UO}_{2}$ was about 20-times higher than that of syn- $\mathrm{UO}_{2}$ (Table 1), indicating that carbonate-promoted the $\mathrm{UO}_{2}$ dissolution more for the biogenic nanoparticles than for the chemogenic material. A plausible cause is the higher initial surface oxidation after pretreatment, in particular the accumulation of $\mathrm{U}(\mathrm{V})$ and $\mathrm{U}(\mathrm{VI})$ near the surface which may give rise to faster detachment of the oxidized uranium species. At the high $\mathrm{pH}$ during the $\mathrm{NaOH}$ treatment of the biogenic $\mathrm{UO}_{2}$, surface oxidation can be more favorable due to higher activity of water radiolysis products and/or faster oxidation kinetics. Through protolysis of $\mathrm{H}_{2} \mathrm{O}_{2}$ the perhydroxy anion $\mathrm{HO}_{2}{ }^{-}$can form and act as an oxidant and a precursor of a chain of radicals that produce an even stronger oxidizing environment (Clarens et al., 2005). To verify the impact of the $\mathrm{NaOH}$ treatment, the reactivity of uncleaned bio- $\mathrm{UO}_{2}$ material has to be determined. The presence of organic matter, in particular when associated with the bio- $\mathrm{UO}_{2}$ surface, may lower the $\mathrm{UO}_{2}$ reactivity and preserve the material against oxidative dissolution (Singer et al., 2009).

\section{CONCLUSIONS}

The long-term stability of biogenic uraninite is a seminal factor governing the success of bioremediation of uraniumcontaminated sites. The stability of nanoparticulate $\mathrm{UO}_{2+x}$ will depend on structural properties that determine surface reactivity and on physicochemical factors that control surface reactions. Building on the recently described structural homology of biogenic nanoparticulate $\mathrm{UO}_{2}$ obtained from S. oneidensis MR-1 and chemogenic $\mathrm{UO}_{2.00}$, the goal of this study was to compare both materials with respect to their intrinsic solubility and dissolution kinetics under a variety of geochemical conditions and to investigate the dissolution mechanisms by bulk XAS and surface-sensitive XPS. The following conclusions are relevant to uranium geochemistry and bioremediation.

1. The thermodynamic solubility data accepted for socalled amorphous $\mathrm{UO}_{2(\mathrm{~s})}$ are suitable in predicting the intrinsic solubility of undoped biogenic $\mathrm{UO}_{2+x}$ nanoparticles in near-neutral water under anoxic conditions.

2. Within the margin of experimental uncertainty and when normalized to surface area, dissolution rates of bio- and chemogenic $\mathrm{UO}_{2+x}$ were similar under carbonate-free reducing and oxidizing conditions, respectively. This similarity enables the modeling of the thermodynamic and kinetic properties of undoped biogenic $\mathrm{UO}_{2+x}$ nanoparticles based on those known for chemogenic $\mathrm{UO}_{2.00}$.

3. In near-neutral water, dissolved inorganic carbon, which is an ubiquitous groundwater component, reversibly promotes the dissolution of $\mathrm{UO}_{2+x}$ not only under strongly oxidizing conditions by forming highly soluble $\mathrm{U}(\mathrm{VI})$-carbonate complexes, but also under nominally reducing conditions, where water and its radiolysis products (e.g., $\mathrm{H}_{2} \mathrm{O}_{2}, \mathrm{O}_{2}$, and radicals) can serve as oxidants. 
This study has shown that intermediate $\mathrm{U}(\mathrm{V})$ species can accumulate on the $\mathrm{UO}_{2+x}$ surface. Formation of soluble $\mathrm{U}(\mathrm{V})$-carbonate complexes is a likely driving force for promoting $\mathrm{UO}_{2+x}$ dissolution under anoxic conditions.

4. The mechanism of $\mathrm{UO}_{2}$ oxidation appears to be more complex than usually assumed. Spectroscopic and analytical data from XPS, XANES, EXAFS, and KPA combined with experimental results from the carbonate treatment of dissolving $\mathrm{UO}_{2.0}$ support the formation of a near-surface layer with an approximate $\mathrm{UO}_{2.25}$ stoichiometry, characterized by a $1: 1$ ratio of $U(I V)$ to $U(V)$. Whereas low oxidant concentrations lead to an intermediate surface $\mathrm{U}(\mathrm{V})$ species, the sequential electron transfer from $U(I V)$ to $U(V)$ to $U(V I)$ becomes favorable under strongly oxidizing conditions.

5. At the most oxidizing conditions studied the detachment of surface U(VI) appears to be rate-limiting in the absence and presence of carbonate up to a threshold concentration above which all accessible U(VI) sites are saturated with carbonate. The accumulated U(VI) can evolve to a metaschoepite-like coating on the $\mathrm{UO}_{2+x}$ surface layer, passivating the $\mathrm{UO}_{2.0}$ core by controlling the uranium solubility and dissolution kinetics. Future studies should quantify the oxidative dissolution process of layered nano-scale $\mathrm{UO}_{2+x}$ materials in the field and explore the environmental significance of natural dopants and $\mathrm{U}(\mathrm{V})$ intermediate species.

\section{ACKNOWLEDGMENTS}

We thank Dan Schwarz and David Clark for providing synthetic $\mathrm{UO}_{2.00}$ material and Satya Chinni for running samples on the KPA. We are grateful to Sabine Ulrich, Edgar Leslie, and Scott Dixon for their assistance in the laboratory. We appreciate helpful discussions with Steven Conradson. We thank the Associate Editor, Dr. Zhu, and two anonymous reviewers who helped improve an earlier draft of this manuscript. Funding was provided by the U.S. Department of Energy, Office of Basic Energy Sciences grant \# DE-FG02-06ER64227, through the linked Grants 1027869 (SSRL), 1027833 (EPFL), and 1027834 (WU). Part of this research was carried out at the Stanford Synchrotron Radiation Lightsource, a national user facility operated by Stanford University on behalf of the U.S. DOE-OBER. Portions of this project were supported by the DOE-BER-funded SSRL Environmental Remediation Science Program and the DOE-BER and NIH-NCRRfunded SSRL Structural Molecular Biology Program. Work carried out at EPFL was funded in part by the Swiss NSF Grant \#20021-113784.

\section{REFERENCES}

Abdelouas A., Lutze W. and Nuttall H. E. (1999) Oxidative dissolution of uraninite precipitated on Navajo sandstone. $J$. Cont. Hydrol. 36(3-4), 353-375.

Allen G. C. and Holmes N. R. (1993) Mixed-valency behavior in some uranium-oxides studies by x-ray photoelectron spectroscopy. Can. J. Appl. Spectrosc. 38(5), 124-130.

Belai N., Frisch M., Ilton E. S., Ravel B. and Cahill C. L. (2008) Pentavalent uranium oxide via reduction of $\left[\mathrm{UO}_{2}\right]^{2+}$ under hydrothermal reaction conditions. Inorg. Chem. 47(21), 1013510140 .
Brooks S. C., Fredrickson J. K., Carroll S. L., Kennedy D. W., Zachara J. M., Plymale A. E., Kelly S. D., Kemner K. M. and Fendorf S. (2003) Inhibition of bacterial U(VI) reduction by calcium. Environ. Sci. Technol. 37(9), 1850-1858.

Bruno J., Casas I., Cera E., De Pablo J., Gimenez J. and Torrero M. E. (1995) Uranium (IV) dioxide and SIMFUEL as chemical analogues of nuclear spent fuel matrix dissolution. A comparison of dissolution results in a standard $\mathrm{NaCl} / \mathrm{NaHCO}_{3}$ solution. Scientific Basis for Nuclear Waste Management XVII. Symposium, vol. 1. pp. 601-608.

Burgos W. D., McDonough J. T., Senko J. M., Zhang G. X., Dohnalkova A. C., Kelly S. D., Gorby Y. and Kemner K. M. (2008) Characterization of uraninite nanoparticles produced by Shewanella oneidensis MR-1. Geochim. Cosmochim. Acta 72(20), 4901-4915.

Casas I., Gimenez J., Marti V., Torrero M. E. and Depablo J. (1994) Kinetic studies of unirradiated $\mathrm{UO}_{2}$ dissolution under oxidizing conditions in batch and flow experiments. Radiochim. Acta 66-67, 23-27.

Chinni S., Anderson C., Ulrich K.-U., Giammar D. E. and Tebo B. M. (2008) Indirect $\mathrm{UO}_{2}$ oxidation by $\mathrm{Mn}(\mathrm{II})$-oxidizing spores of Bacillus sp. strain SG-1 and the effect of U and Mn concentrations. Environ. Sci. Technol. 42(23), 8709-8714.

Christensen H. (1998) Calculations simulating spent-fuel leaching experiments. Nucl. Technol. 124(2), 165-174.

Christensen H., Sunder S. and Shoesmith D. W. (1994) Oxidation of nuclear fuel $\left(\mathrm{UO}_{2}\right)$ by the products of water radiolysis: development of a kinetic model. J. Alloys Comp. 213(214), 9399.

Clarens F., de Pablo J., Casas I., Gimenez J., Rovira M., Merino J., Cera E., Bruno J., Quinones J. and Martinez-Esparza A. (2005) The oxidative dissolution of unirradiated $\mathrm{UO}_{2}$ by hydrogen peroxide as a function of pH. J. Nucl. Mater. 345(2-3), 225231.

Conradson S. D., Begg B. D., Clark D. L., den Auwer C., Ding M., Dorhout P. K., Espinosa-Faller F. J., Gordon P. L., Haire R. G., Hess N. J., Hess R. F., Keogh D. W., Lander G. H., Manara D., Morales L. A., Neu M. P., Paviet-Hartmann P., Rebizant J., Rondinella V. V., Runde W., Tait C. D., Veirs D. K., Villella P. M. and Wastin F. (2005) Charge distribution and local structure and speciation in the $\mathrm{UO}_{2+\mathrm{x}}$ and $\mathrm{PuO}_{2+\mathrm{x}}$ binary oxides for $x \leqslant 0.25$. J. Solid State Chem. 178(2), 521-535.

Conradson S. D., Manara D., Wastin F., Clark D. L., Lander G. H., Morales L. A., Rebizant J. and Rondinella V. V. (2004) Local structure and charge distribution in the $\mathrm{UO}_{2}-\mathrm{U}_{4} \mathrm{O}_{9}$ system. Inorg. Chem. 43(22), 6922-6935.

de Pablo J., Casas I., Gimenez J., Marti V. and Torrero M. E. (1996) Solid surface evolution model to predict uranium release from unirradiated $\mathrm{UO}_{2}$ and nuclear spent fuel dissolution under oxidizing conditions. J. Nucl. Mater. 232(2-3), 138-145.

de Pablo J., Casas I., Gimenez J., Molera M., Rovira M., Duro L. and Bruno J. (1999) The oxidative dissolution mechanism of uranium dioxide. I. The effect of temperature in hydrogen carbonate medium. Geochim. Cosmochim. Acta 63(19/20), 3097-3103.

Docrat T. I., Mosselmans J. F. W., Charnock J. M., Whiteley M. W., Collison D., Livens F. R., Jones C. and Edmiston M. J. (1999) X-ray absorption spectroscopy of tricarbonatodioxouranate $(\mathrm{V}),\left[\mathrm{UO}_{2}\left(\mathrm{CO}_{3}\right)_{3}\right]^{5-}$, in aqueous solution. Inorg. Chem. 38(8), 1879-1882.

Dong W. M. and Brooks S. C. (2006) Determination of the formation constants of ternary complexes of uranyl and carbonate with alkaline earth metals $\left(\mathrm{Mg}^{2+}, \mathrm{Ca}^{2+}, \mathrm{Sr}^{2+}\right.$, and $\mathrm{Ba}^{2+}$ ) using anion exchange method. Environ. Sci. Technol. 40(15), 4689-4695. 
Eriksen T. E., Eklund U. B., Werme L. and Bruno J. (1995) Dissolution of irradiated fuel: a radiolytic mass balance study. J. Nucl. Mater. 227(1-2), 76-82.

Finch R. J. and Ewing R. C. (1992) The corrosion of uraninite under oxidizing conditions. J. Nucl. Mater. 190, 133-156.

Finneran K. T., Housewright M. E. and Lovley D. R. (2002) Multiple influences of nitrate on uranium solubility during bioremediation of uranium-contaminated subsurface sediments. Environ. Microbiol. 4(9), 510-516.

Frazier S. W., Kretzschmar R. and Kraemer S. M. (2005) Bacterial siderophores promote dissolution of $\mathrm{UO}_{2}$ under reducing conditions. Environ. Sci. Technol. 39(15), 5709-5715.

Fredrickson J. K., Zachara J. M., Kennedy D. W., Liu C. X., Duff M. C., Hunter D. B. and Dohnalkova A. (2002) Influence of $\mathrm{Mn}$ oxides on the reduction of uranium(VI) by the metalreducing bacterium Shewanella putrefaciens. Geochim. Cosmochim. Acta 66(18), 3247-3262.

Fredrickson J. K., Zachara J. M., Marshall M. J. and Beliaev A. S. (2007) Biogeochemical mechanisms controlling reduced radionuclide particle properties and stability. In $2^{\text {nd }}$ Annual DOEERSP PI Meeting: Abstracts. LBNL-59453 Abs. 2007, Lawrence Berkeley National Laboratory, p. 44.

Gimenez J., Clarens F., Casas I., Rovira M., de Pablo J. and Bruno J. (2005) Oxidation and dissolution of $\mathrm{UO}_{2}$ in bicarbonate media: implications for the spent nuclear fuel oxidative dissolution mechanism. J. Nucl. Mater. 345(2-3), 232-238.

Ginder-Vogel M., Criddle C. S. and Fendorf S. (2006) Thermodynamic constraints on the oxidation of biogenic $\mathrm{UO}_{2}$ by Fe(III) (hydr)oxides. Environ. Sci. Technol. 40(11), 3544 3550.

Goldik J. S., Nesbitt H. W., Noel J. J. and Shoesmith D. W. (2004) Surface electrochemistry of $\mathrm{UO}_{2}$ in dilute alkaline hydrogen peroxide solutions. Electrochim. Acta 49(11), 1699-1709.

Gorby Y. A. and Lovley D. R. (1992) Enzymic uranium precipitation. Environ. Sci. Technol. 26(1), 205-207.

Gu B. H., Yan H., Zhou P., Watson D. B., Park M. and Istok J. (2005) Natural humics impact uranium bioreduction and oxidation. Environ. Sci. Technol. 39(14), 5268-5275.

Guillaumont R., Fanghänel T., Fuger J., Grenthe I., Neck V., Palmer D. A. and Rand M. H. (2003) Update on the chemical thermodynamics of uranium, neptunium, plutonium, americium and technetium. Elsevier.

Ilton E. S. and Bagus P. S. (2008) Ligand field effects on the multiplet structure of the U4f XPS of $\mathrm{UO}_{2}$. Surf. Sci. 602(5), 1114-1121.

Ilton E. S., Boily J. F. and Bagus P. S. (2007) Beam induced reduction of $\mathrm{U}(\mathrm{VI})$ during X-ray photoelectron spectroscopy: the utility of the U4f satellite structure for identifying uranium oxidation states in mixed valence uranium oxides. Surf. Sci. 601(4), 908-916.

Ilton E. S., Haiduc A., Cahill C. L. and Felmy A. R. (2005) Mica surfaces stabilize pentavalent uranium. Inorg. Chem. 44(9), 2986-2988.

Ilton E. S., Haiduc A., Moses C. O., Heald S. M., Elbert D. C. and Veblen D. R. (2004) Heterogeneous reduction of uranyl by micas: crystal chemical and solution controls. Geochim. Cosmochim. Acta 68(11), 2417-2435.

Janeczek J. and Ewing R. C. (1992a) Dissolution and alteration of uraninite under reducing conditions. J. Nucl. Mater. 190, 157173.

Janeczek J. and Ewing R. C. (1992b) Structural formula of uraninite. J. Nucl. Mater. 190, 128-132.

Jang J. H., Dempsey B. A. and Burgos W. D. (2006) Solubility of schoepite: comparison and selection of complexation constants for U(VI). Water Res. 40(14), 2738-2746.
Kraemer S. M. and Hering J. G. (1997) Influence of solution saturation state on the kinetics of ligand-controlled dissolution of oxide phases. Geochim. Cosmochim. Acta 61(14), 2855-2866.

Kubatko K. A. H., Helean K. B., Navrotsky A. and Burns P. C. (2003) Stability of peroxide-containing uranyl minerals. Science 302(5648), 1191-1193.

Langmuir D. (1978) Uranium solution-mineral equilibria at low temperatures with applications to sedimentary ore deposits. Geochim. Cosmochim. Acta 42(6, Part 1), 547-569.

Lasaga A. C., Soler J. M., Ganor J., Burch T. E. and Nagy K. L. (1994) Chemical-weathering rate laws and global geochemical cycles. Geochim. Cosmochim. Acta 58(10), 2361-2386.

Lovley D. R. and Phillips E. J. P. (1992) Bioremediation of uranium contamination with enzymatic uranium reduction. Environ. Sci. Technol. 26(11), 2228-2234.

Lovley D. R., Phillips E. J. P., Gorby Y. A. and Landa E. R. (1991) Microbial reduction of uranium. Nature 350, 413-416.

Moon H. S., Komlos J. and Jaffe P. R. (2007) Uranium reoxidation in previously bioreduced sediment by dissolved oxygen and nitrate. Environ. Sci. Technol. 41(13), 4587-4592.

N'Guessan A. L., Vrionis H. A., Resch C. T., Long P. E. and Lovley D. R. (2008) Sustained removal of uranium from contaminated groundwater following stimulation of dissimilatory metal reduction. Environ. Sci. Technol. 42(8), 2999-3004.

Pierce E. M., Icenhower J. P., Serne R. J. and Catalano J. G. (2005) Experimental determination of $\mathrm{UO}_{2}(\mathrm{cr})$ dissolution kinetics: effects of solution saturation state and $\mathrm{pH}$. J. Nucl. Mater. 345(2-3), 206-218.

Rehr J. J., Albers R. C. and Zabinsky S. I. (1992) High-order multiple-scattering calculations of X-ray absorption fine structure. Phys. Rev. Lett. 69(23), 3397-3400.

Renshaw J. C., Lloyd J. R. and Livens F. R. (2007) Microbial interactions with actinides and long-lived fission products. Comptes Rendus Chimie 10(10-11), 1067-1077.

Santos B. G., Nesbitt H. W., Noel J. J. and Shoesmith D. W. (2004) X-ray photoelectron spectroscopy study of anodically oxidized SIMFUEL surfaces. Electrochim. Acta 49(11), 1863-1873.

Santos B. G., Noel J. J. and Shoesmith D. W. (2006) The effect of $\mathrm{pH}$ on the anodic dissolution of SIMFUEL $\left(\mathrm{UO}_{2}\right)$. J. Electroanal. Chem. 586(1), 1-11.

Schecher W. D. and McAvoy D. C. (1998) MINEQL+: a chemical equilibrium modeling system, version 4.5. Environmental Research Software.

Schofield E. J., Veeramani H., Sharp J. O., Suvorova E., BernierLatmani R., Mehta A., Stahlman J., Webb S. M., Clark D. L., Conradson S. D., Ilton E. S. and Bargar J. R. (2008) Structure of biogenic uraninite produced by Shewanella oneidensis strain MR-1. Environ. Sci. Technol. 42(21), 7898-7904.

Senko J. M., Istok J. D., Suflita J. M. and Krumholz L. R. (2002) In-situ evidence for uranium immobilization and remobilization. Environ. Sci. Technol. 36(7), 1491-1496.

Senko J. M., Kelly S. D., Dohnalkova A. C., McDonough J. T., Kemner K. M. and Burgos W. D. (2007) The effect of U(VI) bioreduction kinetics on subsequent reoxidation of biogenic U(IV). Geochim. Cosmochim. Acta 71(19), 4644-4654.

Senko J. M., Mohamed Y., Dewers T. A. and Krumholz L. R. (2005a) Role for Fe(III) minerals in nitrate-dependent microbial U(IV) oxidation. Environ. Sci. Technol. 39(8), 2529-2536.

Senko J. M., Suflita J. M. and Krumholz L. R. (2005b) Geochemical controls on microbial nitrate-dependent U(IV) oxidation. Geomicrobiol. J. 22(7-8), 371-378.

Shoesmith D. W. (2000) Fuel corrosion processes under waste disposal conditions. J. Nucl. Mater. 282, 1-31.

Singer D. M., Farges F. and Brown G. E. (2007) Biogenic $\mathrm{UO}_{2}-$ characterization and surface reactivity. Am. Inst. Phys. Conf. Proc. $13^{\text {th }}$ Int XAFS Conf. 882(1), 277-279. 
Singer D. M., Farges F. and Brown, Jr., G. E. (2009) Biogenic nanoparticulate $\mathrm{UO}_{2}$ : synthesis, characterization, and factors affecting surface reactivity. Geochim. Cosmochim. Acta 73(12), 3593-3611.

Suzuki Y. and Suko T. (2006) Geomicrobiological factors that control uranium mobility in the environment: update on recent advances in the bioremediation of uranium-contaminated sites. J. Miner. Petrol. Sci. 101(6), 299-307.

Thomas G. F. and Till G. (1984) The dissolution of unirradiated $\mathrm{UO}_{2}$ fuel pellets under simulated disposal conditions. Nucl. Chem. Waste Manage. 5(2), 141-147.

Torrero M. E., Baraj E., De Pablo J., Gimenez J. and Casas I. (1997) Kinetics of corrosion and dissolution of uranium dioxide as a function of pH. Int. J. Chem. Kinet. 29(4), 261-267.

Ulrich K. U., Singh A., Schofield E. J., Bargar J. R., Veeramani H., Sharp J. O., Bernier-Latmani R. and Giammar D. E. (2008) Dissolution of biogenic and synthetic $\mathrm{UO}_{2}$ under varied reducing conditions. Environ. Sci. Technol. 42(15), 5600-5606.

Wall J. D. and Krumholz L. R. (2006) Uranium reduction. Annu. Rev. Microbiol. 60, 149-166.

Wan J. M., Tokunaga T. K., Brodie E., Wang Z. M., Zheng Z. P., Herman D., Hazen T. C., Firestone M. K. and Sutton S. R. (2005)
Reoxidation of bioreduced uranium under reducing conditions. Environ. Sci. Technol. 39(16), 6162-6169.

Webb S. M. (2005) SIXPack: a graphical user interface for XAS analysis using IFEFFIT. Phys. Scripta T115, 1011-1014.

Wu W. M., Carley J., Luo J., Ginder-Vogel M. A., Cardenas E., Leigh M. B., Hwang C. C., Kelly S. D., Ruan C. M., Wu L. Y., Van Nostrand J., Gentry T., Lowe K., Mehlhorn T., Carroll S., Luo W. S., Fields M. W., Gu B. H., Watson D., Kemner K. M., Marsh T., Tiedje J., Zhou J. Z., Fendorf S., Kitanidis P. K., Jardine P. M. and Criddle C. S. (2007) In situ bioreduction of uranium (VI) to submicromolar levels and reoxidation by dissolved oxygen. Environ. Sci. Technol. 41(16), 5716-5723.

Zhong L. R., Liu C. X., Zachara J. M., Kennedy D. W., Szecsody J. E. and Wood B. (2005) Oxidative remobilization of biogenic uranium(IV) precipitates: effects of iron(II) and pH. J. Environ. Qual. 34(5), 1763-1771.

Zhou P. and Gu B. H. (2005) Extraction of oxidized and reduced forms of uranium from contaminated soils: effects of carbonate concentration and pH. Environ. Sci. Technol. 39(12), 44354440 